\title{
4. Detectives, Traces, and Repetition in THE EXPLOITS OF ELAINE
}

\begin{abstract}
Chapter 4 focuses on a single serial, Pathe's The Exploits of Elaine (1915), which substantiates film serials' crime fiction heritage, and calls for a critical reflection of the 'serial-queen melodrama'. The serial features numerous elements that became generic to film serials in later years, such as the detective, scientific gadgets, or the masked villain. It thus benefited from the success of crime fiction in the 1910s but lacked the narrative voice that untangles the mystery. Drawing on Walter Benjamin's introduction of the detective as a counterpart to the flâneur, the chapter proposes that viewers themselves become detectives as they connect tangentially related anecdotes and identify the mechanics of both the mystery and the narrative, engaging in 'operational detection'-a mode of film viewing that informs both silent- and sound-era serials.
\end{abstract}

Keywords: The Exploits of Elaine, Pearl White, Walter Benjamin, modernity, flâneur, detective

And when we had absolutely completed every particle of the furniture in this way, we examined the house itself. We divided its entire surface into compartments, which we numbered, so that none might be missed; then we scrutinized each individual square inch throughout the premises, including the two houses immediately adjoining, with the microscope, as before. (Poe 1841b: 50o)

Although The Exploits of Elaine (Pathe, 1915) is often listed as another example of the serial-queen melodrama genre - an association that is based on its alliterated title and Pearl White's lead role - the serial also, or perhaps first and foremost, adapts popular detective fiction. Instead of being a self-reliant heroine, Elaine is a damsel in distress, which prompted

Brasch, I., Film Serials and the American Cinema, 1910-1940: Operational Detection, Amsterdam University Press, 2018. DOI: 10.5117/9789462986527/CHO4 
a contemporaneous reviewer to claim that 'it would be more accurate to say that Elaine is exploited rather than that she carries out any exploits' (Pangburn 1915). Craig Kennedy (Arnold Daly), the hero coming to her rescue, is just as much the serial's protagonist. Rather than being original to Pathe's serial, Kennedy was an established serial figure, ${ }^{1}$ a popular fictional detective who appeared regularly in a series of short stories in the Cosmopolitan magazine between 1910 and 1918. Arthur B. Reeve's stories narrate Kennedy's investigations from the perspective of his friend and comrade, a young journalist called Walter Jameson: an arrangement that resembles earlier detective fiction duos, most notably Poe's C. Auguste Dupin and his unnamed narrator-companion, and Conan Doyle's Sherlock Holmes and Dr. Watson. Whereas these well-known forefathers proclaimed ratiocination and deduction, Kennedy is a Columbia University professor who sets out to apply scientific methods and technological inventions to crime detection. As a result, Reeve's stories always circle around one or more actual or fictional marvels of technology (Panek 2006: 77). The same focus on the presentation of modern technology informs THE ExPLOITs of ELAINE and its accompanying serial novel, which appeared in the newspapers of William Randolph Hearst's syndicate alongside the release of the filmic episodes. ${ }^{2}$ In its showcasing of novel or fictional gadgets, the film serial incorporates visual and narrative themes that similarly permeate later serials of both the silent and the sound eras. More generally, ThE Exploits of ElAINE's combination of a fictional detective, a murder plot, a masked master villain, and gunslinging action seem to prefigure elements that were to become

1 Ruth Mayer and Shane Denson define 'serial figures' as recurring fictional characters that appear in a variety of media in the twentieth and twenty-first centuries, for instance Dracula, Tarzan, Frankenstein's Monster, or Fu Manchu. Many of these figures date back to the heyday of media proliferation between 1880 and 196o (Denson \& Mayer 2012b: 185; see also 2012a). Although he is less known today, Detective Craig Kennedy appeared in short stories and numerous, often serial novels from 1910 to the mid-1930s. In addition to Pathe's The Exploits of Elaine, ThE New Exploits of Elaine, and The Romance of Elaine in 1915, the character reappeared in at least two more silent serials-The CARTer CASE (Oliver, 1919) and The RAdio Detective (Universal, 1926-before returning in the 1936 sound serial The CLUTCHING HAND (Weiss Productions). The pressbook for the latter includes a biographical sketch of the detective as compiled from the full range of Detective Kennedy stories and films, titled 'Craig Kennedy Is a Very Real Person'.

2 Depending on an individual cinema's location, the film releases at times followed a few weeks after the appearance of the print chapter (Stamp 2000:117-118; see chapter 3 of this volume). Cosmopolitan also belonged to Hearst's syndicate at the time, however, the magazine did not feature The Exploits of ElAine. It did however use set photographs from the production of the serial to illustrate Hugo Münsterberg's article 'Why We Go to the Movies', but without mentioning the serial (Münsterberg 1915: 26-27). 
generic to later film serials, especially in the 1920s and 1930s. This chapter's exclusive focus on this particular serial therefore introduces narrative and visual themes and details a related mode of viewer address that is shared by later serials to an extent that questions the so far comparatively strict separation of film serial scholarship into the eras of silent and sound film.

Although The Exploits of ElAine provides ample space for the action and pathos of melodrama, Kennedy's approach to detection resembles earlier detective fiction in terms of his scrutiny, similar to Poe's description at the beginning of this chapter. Just as in 'The Purloined Letter', the microscopic view is futile without the genius detective. But whereas analysis in Poe's and Conan Doyle's stories is usually conducted retrospectively, detection in THE EXPLOITS OF ElaINE takes place in synchronization with the unfolding of the crime, which is both necessitated and foregrounded by the story's week-to-week serialization. The showcasing of detection and technology in the filmic episodes of THE Exploits of ELAINE draws on and feeds into the presentism and presentationalism of film serial storytelling as outlined in the previous chapter. Moreover, the serial combines and portrays the multiple dimensions of the operational aesthetic in its foregrounding of narrative and technological processes as well as of film itself as a process. As this chapter will show, the combination of presentational storytelling and detective plots, and particularly the presentation of medially recorded traces and clues to an attentive audience, updates the classic detective story to the media modernity of the twentieth century and transforms the viewing experience into an act of operational detection.

This chapter considers film viewers as renditions of Walter Benjamin's figure of the detective, as it is formulated within and alongside his conceptualization of the flâneur. The type of the flâneur has been taken up most prominently by Anne Friedberg, Miriam Hansen, and Vanessa R. Schwartz as a means to conceptualize changing perceptive subject positions in the twentieth century. In a less widely acknowledged adaptation of Benjamin's work to film studies, Tom Gunning has related transitional film practices to the figure of the detective, a less prominent alternative to the flâneur in the Arcades Project (Friedberg 1993, 1998; Gunning 1995b, 1997, 2003; Hansen 1987; Schwartz 1998). In the following, I will employ Benjamin's descriptions of a bourgeois nineteenth-century experience of urban Paris and its relation to the detective story as a backdrop for a study of THE ExPLOITS OF ElAINE that understands the serial as performing a self-conscious update of the classic detective story in accordance with the experience of modernity in the early twentieth century. The serial's imagery and mise-en-scène create visual spaces that resemble the secluded intérieur as described in the Arcades 
Project, and its plotlines circle around the problem of the identification of the individual in the crowd as outlined by Benjamin. Yet the serial also questions the integrity of the interieur and the possibility of tracing the individual in the first place and thereby disables the successful deductive efforts of the detective. As the chapter will describe in more detail, THE EXPLOITS OF ELAINE negates its protagonist detective's capacity to deduce the solution to a criminal mystery from traces left in the bourgeois parlor. Instead, the serial uses its diegetically showcased technologies to feed recorded clues to its viewers, who take on the task of detection. In this way, THE EXPLOITS OF ELAINE updates the detective story according to the promises and affordances of the filmic medium. As the second part of the chapter will show, the viewers' efforts at detection depend upon practices of surveillance and particularly on the film camera as a surveilling agent. In this context, mediated perception and film's capability to repeat self-reflexively showcase cinematic storytelling and the mechanics of the detective story, effecting the eventual replacement of the diegetic genius detective with the viewer's perceptive activity of operational detection.

\section{Detective Kennedy, Traces, and the Intérieur}

The first episode of ThE ExPLOITS OF ELAINE appeared in cinemas in the United States on 28 December 1914, immediately following the final episode of Pathe's successful The Perils of PAUline (1914). Elaine met with great success, sparking two sequels in 1915: THE NEW EXPLOITS OF ELAINE and THE ROMANCE OF ElAINE. The serial was in fact profitable enough to serve as an excuse for Pathe's exchange managers to raise their own salaries by twentyfive percent, which they announced when the serial's profits surpassed the one-million-dollar mark (Motion Picture News, 1915c; cf. Dahlquist 2013b: 14). The serial's plot concerns Detective Kennedy and his friend Walter Jameson's (Creighton Hale) pursuit of a sinister master villain called the Clutching Hand (Sheldon Lewis). They aim to avenge the murder of Taylor Dodge and save his daughter Elaine (Pearl White) from the villain's attempts to murder her as well. Together with Elaine and her family lawyer Perry Bennett (Sheldon Lewis), Kennedy and Jameson try to capture and identify the masked villain in a pursuit that covers the serial's fourteen episodes. Meanwhile, both Bennett and Kennedy are also romantically interested in Elaine, with Kennedy eventually winning her heart.

The serial's initial episode both establishes Kennedy as a traditional private detective and rejects the narrative implications of classically 


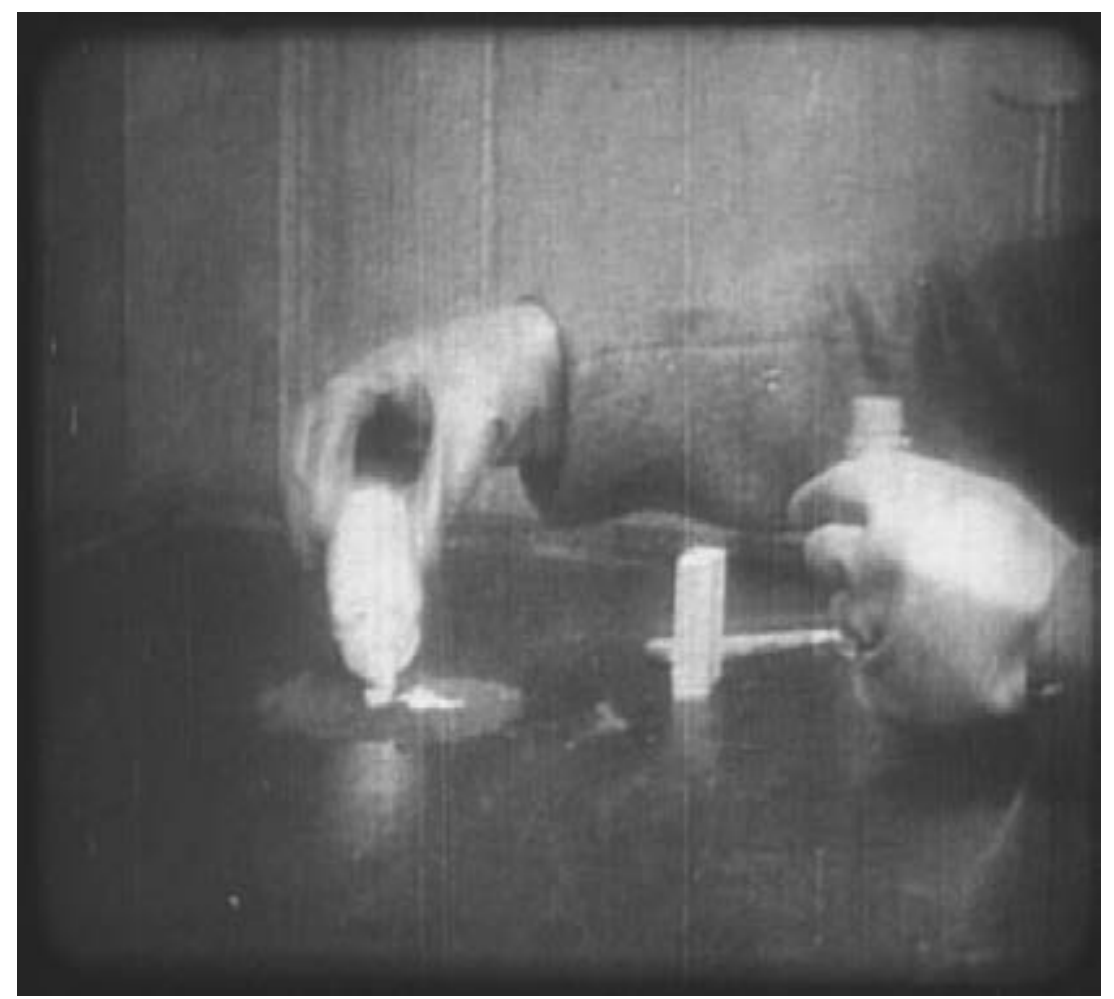

12. From The Exploits of Elaine, episode one, 'The Clutching Hand': The eponymous criminal pours thermite on the top of the safe.

constructed detective stories. The episode shows how the Clutching Hand enters the Dodge residence, murders Elaine's father with vaporized poison, and breaks into the safe in his study. The camera minutely follows the criminal's maneuvers as he burns the top of the safe with a chemical powder and leaves intentional fingerprints on a bust of Shakespeare that decorates the top of the safe. A little later, Detective Kennedy studies the villain's traces, identifies the chemical powder as thermite, and examines the fingerprints on the bust only to find that they are his own. ${ }^{3}$

This narrative sequence establishes Kennedy's prowess in detective work and science. In fact, the first shot of him in the serial portrays him in his laboratory as seen through a magnifying glass — a shot that already correlates Sherlockian imagery with laboratory work. Whereas Kennedy,

3 The idea of faked fingerprints had been introduced in the French serial FANTômas (Gaumont, 1913) a year earlier. 


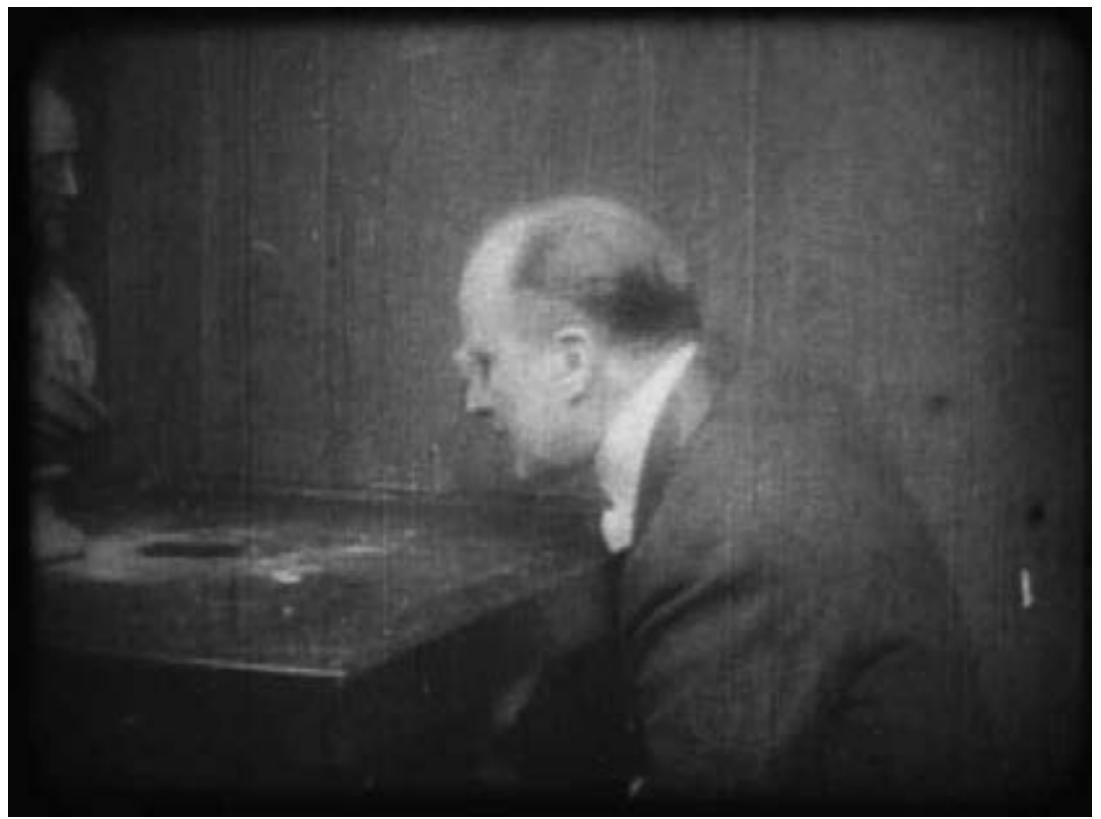

13. Detective Kennedy inspects the hole that was previously hidden by the bust of Shakespeare (The Exploits of Elaine, episode 1, 'The Clutching Hand').

just like his literary predecessors, arrives on the scene to examine the murderer's traces in retrospect, the narrative organization of this episode tells its story very much in line with the presentist and presentational mode of film serials more generally: it portrays the action chronologically in the present tense and it meticulously presents the villain's action before allowing the detective to enter the scene. This narrative strategy entails a large number of close-ups of objects, which enables the film's viewers to trace the villain's steps before the arrival of the detective. Rather than pointing out what we know already, Kennedy's function then is to explain and interpret, that is, to name the chemical powder 'thermite' and to identify the fake fingerprints as his own. In this manner, both Kennedy and the theater audience of ThE ExPLOITS OF ElAINE emerge as detectives.

Benjamin relates the perceptive activity performed by detectives to his famous description of the flâneur. As part of the larger Arcades Project, the detective and the flâneur emerge from the arcade, a newly created public space in nineteenth-century France. Open streets with small department stores were roofed with glass to construct a space that is neither fully inside nor fully outside, but the exterior was screened in to function as an 


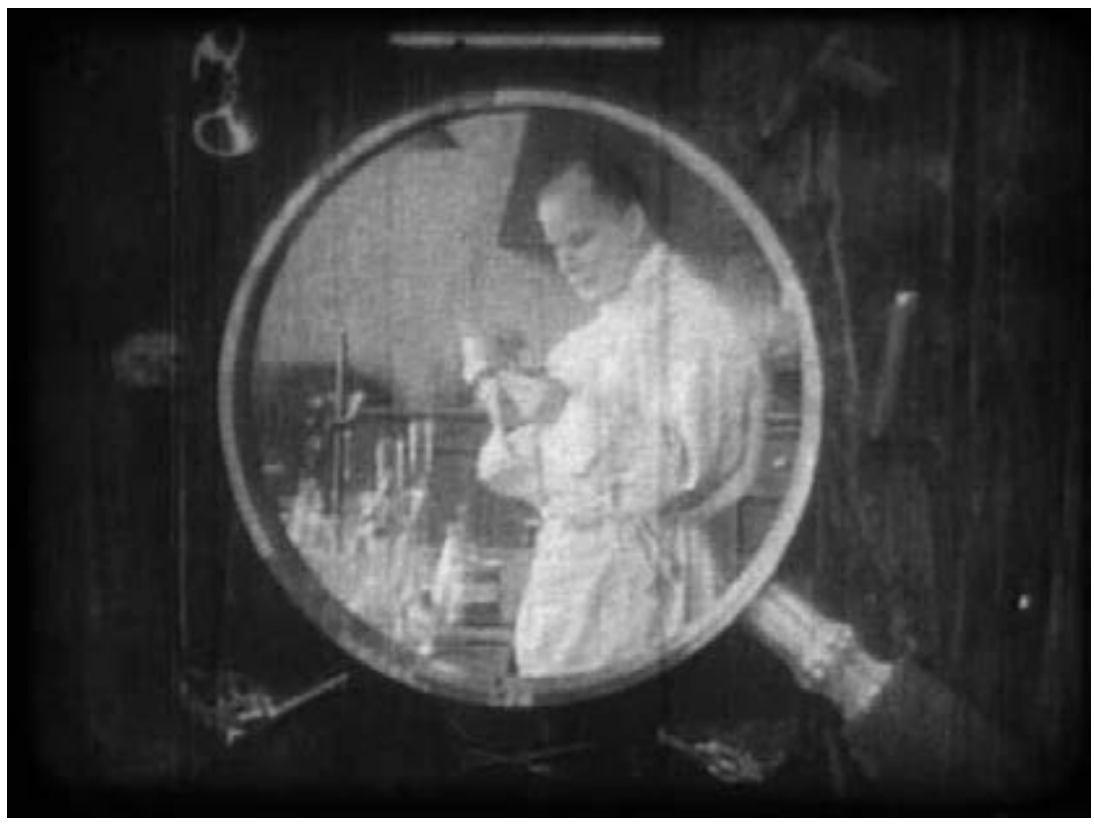

14. Detective Kennedy in his laboratory (The Exploits of Elaine, episode 1, 'The Clutching Hand').

extended interior space. This space is home to the flâneur, the 'chronicler and philosopher' of the arcades (Benjamin 2003b: 19). For him, the arcade turns the crowded streets of an increasing urbanization into a familiar, interior environment. ${ }^{4}$ Benjamin describes the flâneur as 'a mirror as vast as the crowd itself, [...] a kaleidoscope endowed with consciousness, which, with each one of its movements, represents the multiplicity of life and the flickering grace of all the elements of life' (1999: M14a, 1). The flâneur always remains in the crowd; he vanishes into it and leaves no trace (Benjamin 2003b: 27). As a 'gentleman of leisure' who ventures through the arcades at his own speed, he is both a symptom of social and industrial-commercial change and its antithesis. The flâneur's refusal to take part in Taylorist industriousness, according to Benjamin, will feed into his eventual demise (p. 30).

The detective, by contrast, is no idler. Instead, the assignment and endeavor to detect provides him with an alibi for his supposed idleness. Whereas the flâneur is not a student of pedestrians who reads their social status, nationality, or character from their outward appearance, the detective

4 For the flâneur, 'more than anywhere else, the street reveals itself in the arcade as the furnished and familiar interior of the masses' (Benjamin 1999: M3a, 4). 
is only seemingly unoccupied when he actually engages in the close observation of a presumed malefactor (1999: M6a, 4; M13a, 2). Benjamin explains the relation of the flâneur and the detective in 'The Paris of the Second Empire in Baudelaire', his first formulation of convolute J, the largest collection of material within the Arcades Project (cf. Buck-Morss 1989: 205). The essay establishes the detective as one subcategory of the flâneur, in addition to the badaud - a distinction that was lost in 'On Some Motifs in Baudelaire', Benjamin's revision of the original essay after Theodor Adorno's criticism (Benjamin 2003a; Buck-Morss 1989: 205). In the earlier essay, Benjamin defines this trinity as follows: 'In the flâneur, the joy of watching prevails over all. It can concentrate on observation; the result is the amateur detective. Or it can stagnate in the rubbernecker; then the flâneur has turned into a badaud' (2003b: 41). Detection thus results from flânerie, but it also supersedes it.

The detective's activities of detection and observation correspond to an increasing skepticism towards the masses. One downside of the masses, Benjamin contends, is that they provide a refuge for what he terms the 'asocial'. Therefore, 'in times of terror, when everyone is something of a conspirator, everybody will be in the position of having to play detective. Flânerie gives the individual the best prospects of doing so' (2003b: 21). Previously nonchalant observers thus become detectives who learn to keep up with the accelerated pace of the metropolis in that they register facts in passing. Doing so, detectives will imagine themselves to be artists (p. 21).

ThE EXPLOITS OF ElAINE stylizes its protagonist detective overtly as a close observer, while the viewers, as I have shown, themselves trace the steps and maneuvers of the Clutching Hand in the serial's first episode ('The Clutching Hand'). Instead of idly following a detective's explanation of a previously terminated criminal activity, they first observe and trace for themselves before they receive additional professional assistance. However, THE EXPLOITS OF ELAINE provides these efforts of detection with a modern twist, updating them to the existing or idealized technological standards of the mid-1910s. The serial itself foregrounds the necessity for such an update when Kennedy finds his own fingerprints on the bust in Taylor Dodge's study. Chemistry, science, and technology are equally available to villains and detectives, and by allowing for a fabrication of fake fingerprints, science enables the villain to anticipate and render helpless the detective's traditional means of detection or ratiocination. Although the first appearance of Kennedy in the initial episode establishes the detective's expertise, it simultaneously demonstrates the insufficiency of traditional methods of detection for a pursuit of the skilled master villain the Clutching Hand. In 
its first episode, THE EXPLOITS of ElAINE thus stresses the inapplicability of established means of detection and related narrative formulae and insists on a modernization or update.

The necessity for this update results particularly from the serial's instantiation and its following disintegration of the secluded bourgeois intérieur. ${ }^{5}$ An extensive collection of notes and references in the Arcades Project refers to the décor of domestic spaces in nineteenth-century France. These notes convey an understanding of the significance of the home as a highly fashioned space, which strives to seclude itself from and define itself in opposition to emerging modernity's urban spaces. Benjamin's notes cast the bourgeois intérieur as a carefully arranged tableau, which is marked by an abundance of material items, especially of fabrics (1999: I3, 7). The set serving as the Dodge home in The Exploits of Elaine is designed in a similar, late-Victorian fashion, with brocade fabrics in carpets, cushions, and curtains, its ornamental wallpaper, as well as its wooden boarding, pillars, and sideboards framing the walls. ${ }^{6}$ The often-shown parlor is of a particularly elaborate design, with a large ornamental desk chair and numerous carefully arranged decorative items such as flower vases, books, and a life-size knight's armor. The parlor and the adjoining study are set up to symbolize the wealth of Taylor Dodge and his daughter, as indicated by the pricey ornamental designs. Meanwhile, the fact that her father keeps a separate study in his house including a bust of Shakespeare signals a certain degree of education, and the cushioned materials and Elaine's pets create a sense of coziness. ${ }^{7}$

The home of Taylor and Elaine Dodge in the serial resonates with Benjamin's description in ways that similarly apply to other films of the era. However, such a set design is of particular relevance in detective fiction because of its capacity to register traces. By means of the trace, Benjamin draws a connection between the interieur and the emergence of detective stories in the mid-nineteenth century: the fabrics and materiality of the

5 Benjamin employs the French term 'intérieur'. The English translation by Howard Eiland and Kevin McLaughlin, however, uses the English 'interior' (see Benjamin 1999). In the following, I will use Benjamin's original term, in accordance with Tom Gunning's use of the term (see Gunning 2003).

6 In the early 19oos, Victorian furniture was still very much around, although alternatives such as Art Nouveau or the Arts and Crafts Movement existed. However, just half a decade after The Exploits of Elaine, the Art Deco of the 1920 sould become much more prominent in film sets.

7 My analyses in this chapter are based on a French release of the serial's first episode; later episodes have been studied in their American release versions. The French release of episode one does not identify the bust as Shakespeare's; however, the newspaper tie-in does. 
intérieur enable an accumulation of traces; they register the marks left by human movement and action, which a skilled eye can reconstruct. ${ }^{8}$ For Benjamin, the cavernous nature of the intérieur invites a dream state of suspended coziness and seclusion from the outside world, and detective fiction is emblematic of the struggle to leave this state of being (1999: I2, 6). This relation of the trace and the intérieur marks Edgar Allan Poe's stories, as Benjamin mentions 'the confrontation with furniture in Poe. Struggle to awake from the collective dream' (1999: I1, 4).

The first episode of The Exploits of Elaine describes two penetrations of the secluded space that wake its inhabitants from their dream-like state of bourgeois comfort. First, the Clutching Hand secretly enters the Dodge family home in the original murder sequence. Additionally, Detective Kennedy's subsequent examination of the crime scene itself constitutes another intrusion. But his efforts at detection fail because the traces left by the Clutching Hand are calculated and coordinated. The fact that he leaves Kennedy's fingerprints on the Shakespearian bust attests to the criminal's control over his own traces and it questions the validity of pursuing detection by means of collecting traces in an age of modern science. The intérieur can be manipulated; consequently, the collection of traces ceases to suffice for thorough detective work in the twentieth century. Whereas Benjamin describes an original dream state and its disruption in detective stories, THE EXPLOITS OF ELAINE now recasts the latter as a product of bygone times and signals a new 'scientific awakening'. 9

This rejection of the intérieur's capacity to register or record traces can also be understood as a logical update of the concept of the intérieur to its appearance in film. Both the bourgeois parlor and the film set are carefully designed spaces in which objects are arranged in 'a visual ensemble' (1999: I3, 7).$^{10}$ However, other notes from the Arcades Project cast the intérieur more in terms of the prop department's warehouse: references to historical periods or occurrences accumulate in a curious bricolage of styles (1999: $\mathrm{I}, 6)$.

8 The corresponding note says: 'Plush— the material in which traces are left especially easily' (Benjamin 1999: I5, 2).

9 More than two decades later, Dick Tracy (Republic, 1937) employs a similar strategy. The initial chapter shows how Tracy quickly finds a murderer by comparing wood chippings left at the murder scene to the chippings used by a puppet player to stuff his puppets. This moment of accuracy and detailed tracing is then quickly followed by the insight that the puppet player is a small part of a larger criminal organization, which cannot be tracked with similar measures but requires a pursuit in real time, with up-to-date technology and quick action (episode 1, 'The Spider Strikes').

10 Benjamin acknowledges this in passing when he notes: 'Development of "The Interior" chapter: entry of the prop into film' (1999: I6, 3). 
What previously appeared as the careful arrangement of fabrics in the nineteenth-century parlor is now cast as a mixture of historical references, which in their combination signify if anything a vague sense of history as such rather than any specific event or historical figure. In film, such accumulations of objects can assume a signifying function within the narrative, but they can also be somewhat coincidently based on the prop cabinets of a respective film studio. ${ }^{11}$ In the nineteenth-century parlor, however, Benjamin denies these props or objects all signification:

Nineteenth-century domestic interior. The space disguises itself-puts on, like an alluring creature, the costumes of moods. The self-satisfied burgher should know something of the feeling that the next room might have witnessed the coronation of Charlemagne as well as the assassination of Henri IV, the signing of the Treaty of Verdun as well as the wedding of Otto and Theophano. In the end, things are merely mannequins, and even the great moments of world history only costumes beneath which they exchange glances of complicity with nothingness, with the petty and the banal. Such nihilism is the innermost core of bourgeois coziness... (1999: I2, 6)

The 'costume of moods' resembles a filmmaking practice of designing spaces as signifiers for a fictional character's emotional state and characterization. The mise-en-scène of the Dodge family home, with a bust in the study and a knight's suit of arms in the parlor, is an accumulation of 'meaningless' objects similar to the nineteenth-century intérieur. In their conglomeration, these objects convey a vague sense of historicity, which registers as an awareness of history as such rather than as a reference to any specific past era or event. This vagueness particularly results from the missing link between objects such as the knight's suit of arms and the bust. In a paradoxical manner, both the nineteenth-century intérieur and Pathe's set designs assembled objects that enabled a room to put on 'costumes of moods' while simultaneously showing 'complicity with nothingness'. This nihilism, as Benjamin calls it, is especially pronounced when supposedly historical objects are reduced to their sheer functionality and materiality_as happens when they become bearers of traces.

At this point, the fragments of the Arcades Project turn the concept of the intérieur inside out, as the objects so far established as embodiments

11 The latter would also account for the frequent reappearance of the knight's armor in Pathe sets, for instance in The Perils of Pauline (1914) and in The House of Hate (1918). 
of nothingness assume a particular meaning and function in a concrete narrative context. That is, objects spontaneously assume a short-term significance or signification in a story, as opposed to the historical meaning they explicitly do not carry. Especially detective fiction assigns individual objects a short-term significance, turning them from mere decorations into narrative props. Their new significance points to a specific outside and to an intrusion from that outside world, in the form of a murderer or burglar, into the secluded bourgeois space. Just as the arcade converted an outside into an interior space, the trace signifies the opening of the intérieur to the outside, thereby terminating the former dream state. Whereas the detective story thus opens up the intérieur and endows previously meaningless objects with agency, THE Exploits of ElAINE evokes the imagery of the detective story - the bourgeois design, the detective with his magnifying glass, the fingerprints - only to self-consciously distance itself from this narrative tradition. The intérieur portrayed in THE ExPLOITS of ElAINE is a penetrable space from the start: before his murder, Taylor Dodge hides important papers in a secret cabinet in the wall. The presence of such a storage place, just as the more visible presence of a safe, already takes into account the possibility of a break-in. The serial then proceeds to stress the lacking seclusion by revealing traces, in the fake fingerprints, as manipulatable in the already permeable space.

Having established this problem space in its introductory episode, the following installments of THE ExPLOITS OF ELAINE rehearse its thoroughly modern solution: science and technology replace the efforts of observation and deduction upon which previous detectives relied. Instead of retrospectively studying the objects of the intérieur, Detective Kennedy installs complex technologies that enable him to either record or monitor activities in a particular space. In this context, the difference between recording and monitoring depends on a distinction of retrospective analysis and simultaneity. Recorded traces can only be analyzed in hindsight. Whereas 'traditional' traces such as fingerprints are always found retrospectively, the recorded traces of THE EXPLOITS of ELAINE have been technologically collected by a previously installed mechanism, for instance a hidden seismograph that records human movement (episode 4, 'The Frozen Safe'). Monitoring, by contrast, implies that a detective is spying on the villain's actions live, aided by visual or audio technologies, for instance by an audio transmission device called the vocaphone (episode 8, 'The Hidden Voice'). As the following passages will outline, THE EXPLOITS OF ELAINE demonstrates technologies for both monitoring and recording, and each particular technology impacts the ways in which the episode narrates its story and its operational aesthetic. 
In the fourth episode, Detective Kennedy installs a hidden seismograph in his apartment, which will enable him to see, in hindsight, whether anyone entered during his absence. Like the Dodge residence, Kennedy's personal apartment is an intérieur that has been opened up: instead of shielding it from intruders, Kennedy merely makes sure he registers them. Instead of preventing crime, he records it. And just as sewing machines were hidden in special furniture in the nineteenth century and television sets in the twentieth, Kennedy's seismograph is hidden in the hallway wall outside his apartment, invisible to the eye (Douglas 1982: 25-27, cf. chapter 2; Spigel 1992: 49). Hiding the mechanism is Kennedy's solution to the question of how to technologically protect his home from intruders without letting the technology itself become the intruder. More importantly, the seismograph technology enables a shift in the nature of the trace: proof of the villain's intrusion now exists only in the form of the graph written by the seismograph — the trace does not, however, register any of his apartment's objects or decorations. Decades after the period which, according to Benjamin, experienced a shift from meaningful objects to objects that only serve as bearers of traces, traces shift once again to now appear as mediated by modern technologies. Traces have lost their carrier objects, which are replaced by carrier media. As a result, the objects of the cinematic intérieur are deprived of even their short-term significance, and traces cease to be physically inscribed other than in the form of abstractions, as in the diagram drawn by the seismograph.

The serial's showcasing of the seismograph mechanism in this chapter corresponds to its larger agenda of displaying modern feats of technology and science. In fact, advertisements for THE ExPLOITS of ELAINE foreground technologies as visual attractions and stress their authenticity. A full-page article announcing the serial's premiere on 28 December 1914, for instance, highlights the fact that the detective in the written short stories 'makes use of genuine scientific methods in the detection of crime' and considers it an 'added value' to the Kennedy short stories from the Cosmopolitan. The article furthermore stresses that the short stories had already helped to sell technological devices to police authorities. 'The author keeps so closely in touch with the newest discoveries in all branches of science', Motion Picture News reports, 'that he is able to solve mysteries by means which are as genuine as they are startling' (Motion Picture News, 1914c). Three months later, a trade press article covering the serial was headlined 'Remarkable Mechanical Devices Used in "Elaine”'. Probably straight from the studio press release, it highlights that 'the various remarkable mechanisms shown are not the product of the studio workshop, but the genuine article, in one instance 


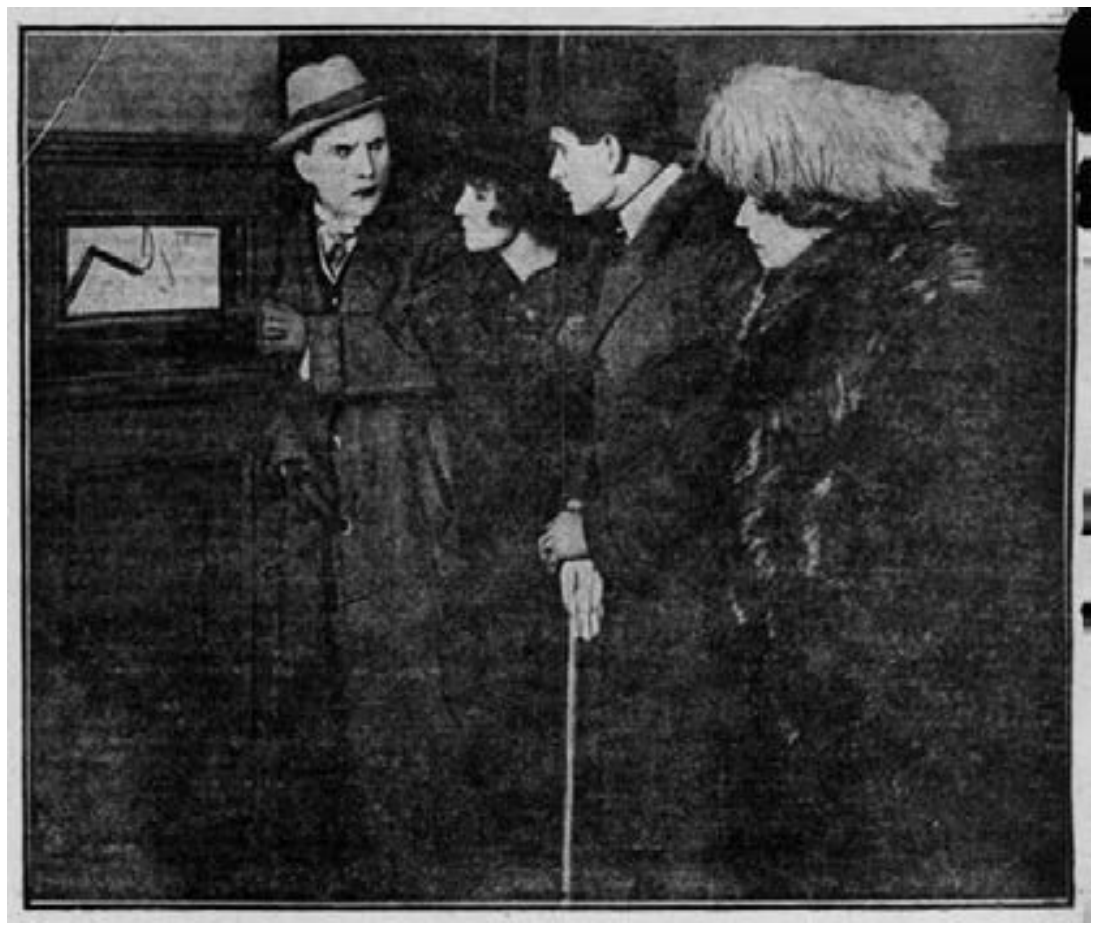

15. Detective Kennedy demonstrates the seismograph. Film still published with the newspaper tie-in for episode four, 'The Frozen Safe' (Reeve 1915).

at least the only one ever produced and tremendously costly' (Motion Picture News, 1915a). In Motography, the same article featured a closing statement in which Theodore Wharton of Pathe Studios stresses that

No, we are not faking any scientific apparatus in "The Exploits of Elaine". We don't have to. The inventors of these different remarkable machines voluntarily offer us the use of their devices, feeling that the use of them in a motion picture with the circulation of "Elaine" cannot help but bring new and valuable publicity. (Motography, 1915)

Such advertisements work with truth claims that resemble those put forth by P.T. Barnum in the 1840 s. They highlight the sincerity of their props and stress that these mechanisms truly function. For theater patrons who regularly read the serial's newspaper tie-in, the corresponding film chapter allowed for a chance to see the mechanism from the story. Just as the descriptions and drawings of incredible exhibition pieces or technological marvels had attracted audiences to curiosity museums or public displays of 
technologies in the nineteenth century and into the twentieth, the promotion articles and the written tie-ins of THE EXPLOITS OF ELAINE attracted audiences and fueled their curiosity by promising visual presentations of the technologies that audiences had previously read about. Simultaneously, this practice lent the serial an air of an educational appeal. Curiosity museums and descriptions and exhibitions of novel technologies always combined entertainment and instruction, and Pathe willingly tapped into this trend. Moreover, this advertising strategy and mode of address corresponds to an understanding of film viewers as Benjaminian detectives: the promised presentation of technological advancement justifies the leisurely time of film viewing just as the task of detection served as an alibi for the flâneur, transforming a leisurely activity into a meaningful but no less entertaining exercise.

Whereas the technologies of THE ExPLOITS OF ELAINE thus turn viewers into detectives through the serial's paratexts, within the serial's narrative, particular technologies serve to register traces and make up for the perceived unreliability of the intérieur. Such a technological registering of traces is not unknown to Benjamin's reflections. Although the intérieur retains its integrity to an extent, the arcades and urban spaces with their vast crowds missed a counterpart to plush in the intérieur. In other words, like the parlor in The ExPLOITS OF ELAINE, the crowd lacked the means to preserve the trace, and Benjamin identifies photography as the solution to the problem. Its invention enabled the identification of the individual and the preservation of an individual's trace: 'Photography made it possible for the first time to preserve permanent and unmistakable traces of a human being. The detective story came into being when this most decisive of all conquests of a person's incognito had been accomplished' (Benjamin 2003b: 27). By resorting to technology to collect and register traces, THE EXPLOITS OF ELAINE thus transfers and adapts the methods of tracing individuals in the crowd to the interieur. As a result, the serial obfuscates the distinction of interior and exterior spaces, as both rely on technology to provide traces.

The serial's eighth chapter, 'The Hidden Voice', is a poignant example of such a technologically enabled connection of spaces and the careful opening up of the intérieur. The chapter begins with a short demonstration of its featured technology, the 'vocaphone', a loud-speaking telephone recently invented by the scientific detective. Kennedy places the intercom device in the apartment of his friend, the journalist Walter Jameson, for a test. Speaking through the vocaphone, Kennedy wakes the sleeping journalist, calling 'Wake up, Jameson'. When the journalist does not reply, he again says 'Come, get up Jameson'. Jameson finally gets out of bed and scans his 
bedroom and an adjoining room for the source of the sound. Anticipating Jameson's search for the vocaphone, Kennedy hid the mechanism under the thick brocade cushions on Jameson's couch. In addition to inaugurating a cheerful game of hide and seek, the invisibility of the vocaphone leaves the secluded interior intact - a necessary precondition for the surprise effect of Kennedy's prank. 'Look on the couch', the detective suggests through the mechanism. And Jameson, upon finding the source of the sound, asks: 'What is that? Good luck Kennedy - to your latest invention'. This early, playful disruption of the intérieur prefigures the chapter's climactic ending, which draws on the viewer's knowledge about the functioning of the vocaphone and, by extension, filmic narration, in multiple ways. All of these contribute to the serial's operational aesthetic, as the following passages will show.

First, the scene provides the showcasing of the vocaphone as promised in the serial's advertising in the trade press and as described in the newspaper tie-in. The chapter thus continues the nineteenth-century trend of exhibiting novel inventions, adapting it for twentieth-century narrative film. Second, the vocaphone functions as a mediator between cinematic spaces similar to the gardener's hose in the 1896 film L'Arroseur Arosé, as outlined in chapter two. As Gunning and, by extension, Lisa Trahair describe, the film shows how a boy steps on a gardener's hose to stop the flow of water and then steps off the hose, causing the water to spurt in the gardener's face. In this short scene, the hose serves to delay the cause-and-effect relationship between the boy and the gardener and thereby brings about the film's short narrative (Gunning 1995a; Trahair 2004; cf. chapter two of this volume). Similarly, the vocaphone connects Kennedy's laboratory and Jameson's bedroom, thereby explaining the narrative cause-and-effect relationship between the two spaces. The presence of the mechanism structures both the interaction of the two characters on screen and the resulting narrative. Third, by establishing the connection between two diegetic spaces, the vocaphone also explains the scene's parallel editing. When Kennedy leans back in his chair and enjoys his prank, the spectators will attribute his enjoyment to Jameson's befuddlement as the latter fails to find the origin of the voice that woke him. This attribution, however, depends as much on an understanding of crosscutting as it does on the narrative connection between Kennedy and Jameson, both of which are explained by means of the vocaphone. In simultaneously foregrounding the technological functioning of the vocaphone, the causes and effects in the narrative, and its cinematographic rendering, the scene thus combines all three elements of an operational aesthetic. The diegetic technological attraction both structures the way the story is told and explains the serial's approach to storytelling. 
This short sequence precedes any other plot development in the episode, and it serves as a comic sketch that ridicules Jameson, who tousles his hair and has obvious difficulties in gaining consciousness after a good night's sleep, whereas Kennedy is up and awake in his laboratory. The comic sketch, however, also demonstrates particular functions of the vocaphone that are crucial for an understanding of the climactic ending of this installment. The scene details that the vocaphone does not need to be picked up in order to transmit sound and that the sound it transmits is loud enough to wake someone, even when the mechanism is hidden under numerous pillows. Jameson's answer then indicates that the vocaphone works two ways: Kennedy can address Jameson and also hear what he replies. This detailed exhibition and explanation of the vocaphone suggests a depiction of an ingenious invention. However, an early intertitle relativizes the remarkableness of Kennedy's invention: "Craig Kennedy, the scientific detective, experiments on his friend Jameson, with his new vocaphone, a recently invented loud speaking phone." Although it is difficult to ascertain how novel the mechanism would have appeared to the serial's first audiences, the simple reference to the telephone frames the vocaphone as new, but not as ground-breaking. After all, it is just a slight alteration from the telephone, which was ubiquitous maybe not yet in private households, but definitely on film screens (cf. Young 2003; see also chapter two of this volume). Rather than its telephonic qualities, it may have been the loud-speaking function of the vocaphone that was remarkable at the time. Sound amplification was one of the major problems to be solved both for phonography and in early advances toward sound film. ${ }^{12}$ The vocaphone is thus a remarkable technology, but its close relation to the telephone simultaneously suggests a certain realism. Instead of exaggerated science fiction, the serial presents a mechanism that is familiar and reasonable enough to be believable.

The vocaphone, the chapter's introduction suggests, enables Kennedy to be aurally and audibly present in the room. This presence is highlighted by the framing of his words, which appear not as intertitles but are written directly into a still of the frame. This visualization of Kennedy's call quite literally fills the room, forming an extra-diegetic mise-en-scène. Furthermore, Kennedy's presence in fact exceeds the diegetic, verisimilar space of Jameson's apartment: the vocaphone seems to combine with the film camera into a larger audiovisual surveillance mechanism. After calling Jameson for the first time, Kennedy presumes that his friend did not get

12 I thank Shane Denson for pointing out sound amplification as the vocaphone's chief attraction. 


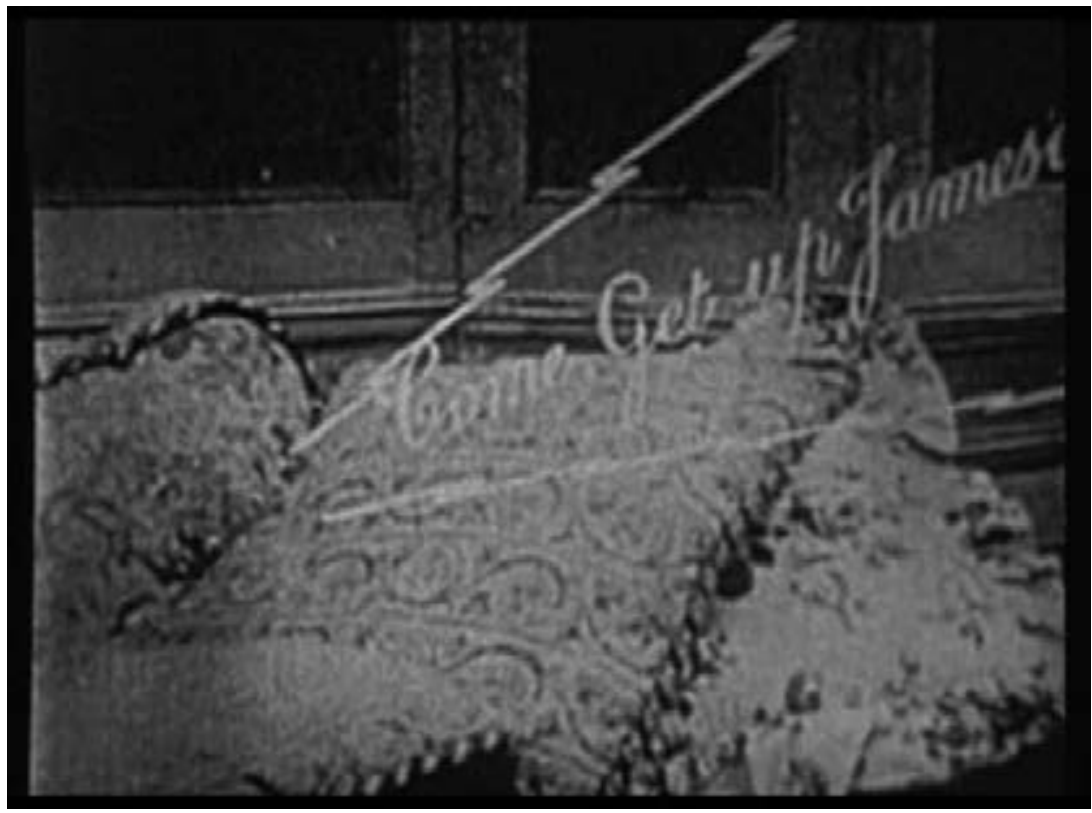

16. The serial's illustration of Kennedy's voice through the vocaphone in THE ExPLOITS OF ELAINE, episode 8 , 'The Hidden Voice'.

out of bed. After the second call, Kennedy somehow knows that Jameson is looking for the origin of the voice. This could be attributed to Kennedy's perfect intuition, but to the audience it may seem as if the mechanisms of the vocaphone and the extra-diegetic camera itself have merged into an omnipresent technological surveillance apparatus.

This knowledge of the intricacies of the vocaphone then becomes useful in the episode's climactic ending, in which the Clutching Hand and one of his henchmen attack Elaine in her parlor. Kennedy had previously hidden the vocaphone in a suit of armor that decorates the room. He listens in on the proceedings of Elaine's predicament and, by means of the vocaphone, leads the villains to believe that they have been trapped. They promptly hurry from the house and Elaine is rescued. For Elaine's safety, Kennedy monitors her parlor: he invests his scientific knowledge to engage in surveillance and to follow the proceedings over at Elaine's. Kennedy is thus a detective in the Benjaminian definition, who employs technology to monitor and observe. In the beginning of the chapter, his scientific interest provides the alibi for the leisurely prank he plays on Jameson. In the final moments of the episode, detection serves to justify Kennedy's methods, which otherwise might appear morally dubious. 


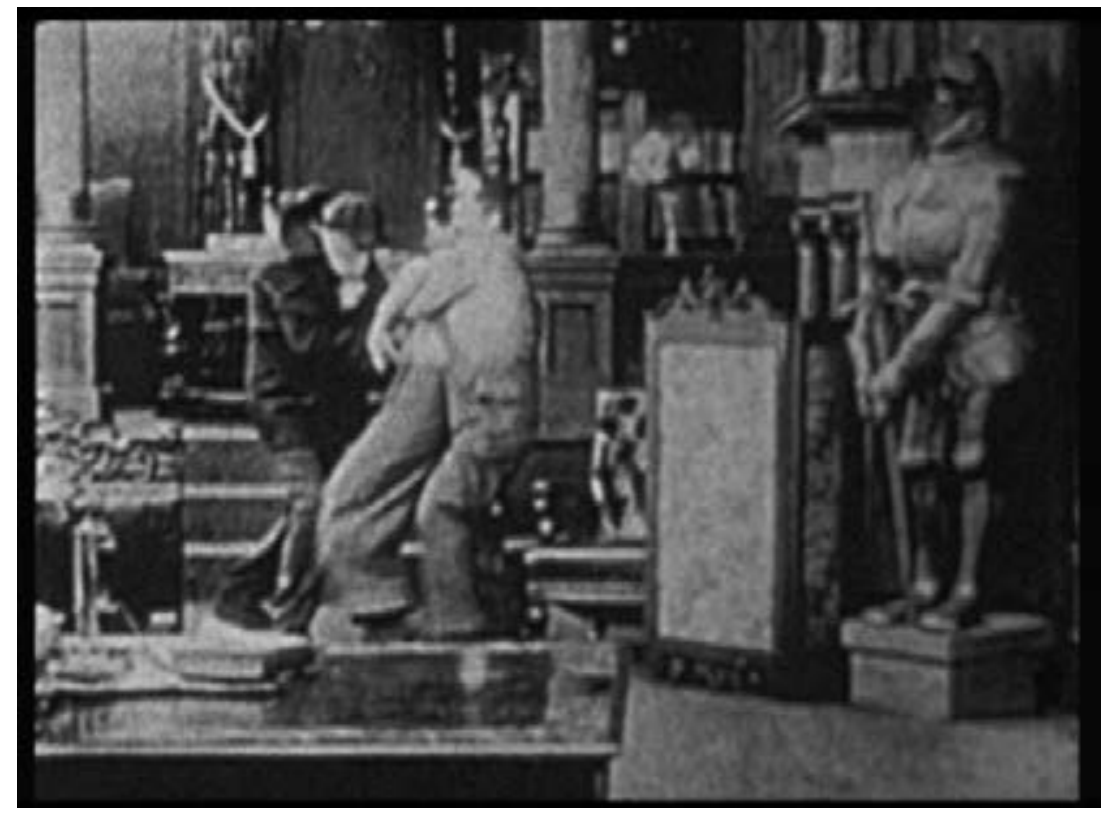

17. The Clutching Hand and a henchman attack Elaine in her parlor. Note also the suit of armor to the right side of the frame (The Exploits of Elaine, episode 8, 'The Hidden Voice').

In both instances, the vocaphone implies an opening of the intérieur to outside influences. Overall, it connects three domestic spaces: Kennedy's laboratory as the communicative hub, Jameson's apartment, and later Elaine's house. Except for in Kennedy's laboratory, the vocaphone is hidden: in Jameson's apartment behind an overabundance of brocade cushions, and in Elaine's parlor inside the knight's suit of armor. The invisibility of the mechanism is pivotal for the narrative, as both Kennedy's prank on Jameson and the way he scares away the villains depend on the respective communication partner's failure to locate the origin of the voice. At the same time, the concealment of mechanisms, which resembles the clever hiding of the seismograph in episode four, is a recurring theme in the serial. Similarly, Benjamin mentions that nineteenth-century Parisians owned covers and sleeves for plenty of objects (2003b: 26). Whereas for Benjamin, such plush covers again served to collect traces, the concealment of technology in THE EXPLOITS OF ELAINE suggests that its intrusion into secluded homes was by no means uncontested. Quite paradoxically, the technology breaks up the intérieur yet simultaneously protects the intérieur against the villainous intruders who are seeking to harm Elaine. The vocaphone is thus on the one hand a means to technologically secure the integrity of the interrieur, and 


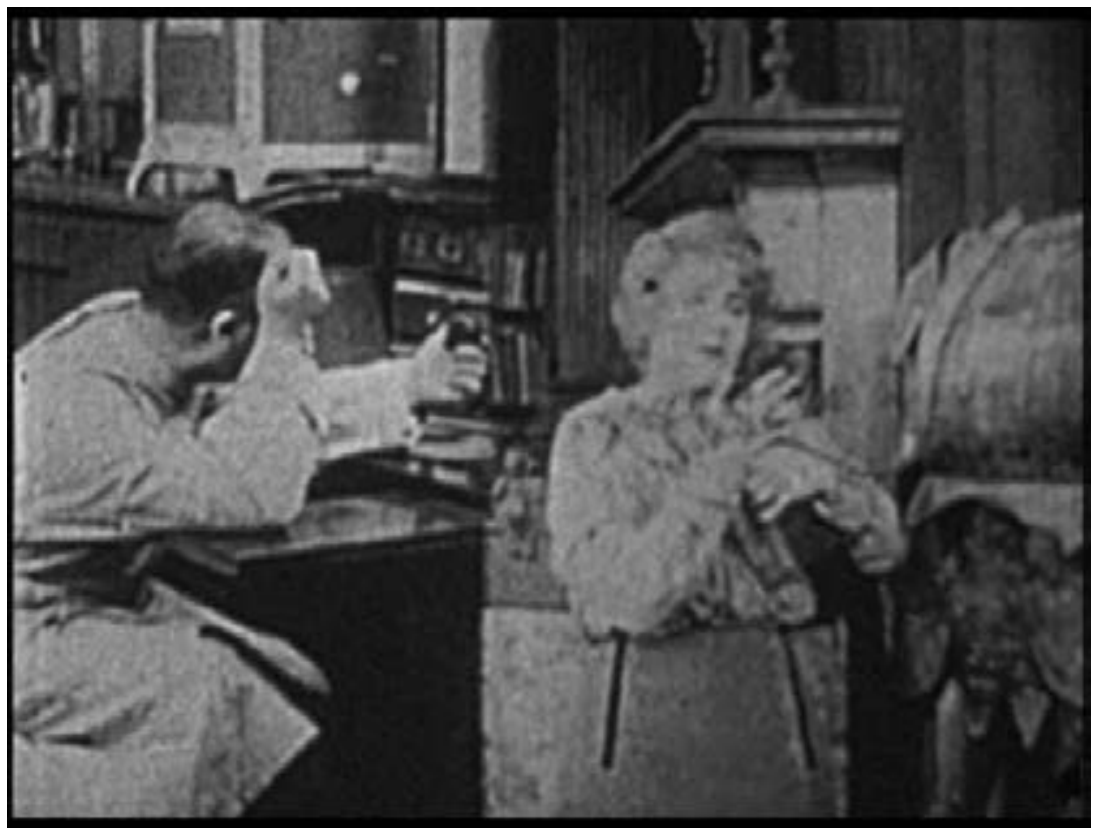

18. Split-screen of Kennedy in front of his vocaphone and Elaine hugging hers (THE EXPLOITS OF ELAINE, episode 8 , 'The Hidden Voice').

on the other hand it itself references the threat posed by villainous forces on the outside. As a consequence, the vocaphone needs to be concealed.

In Elaine's house, the vocaphone is hidden in a knight's suit of armor, that is, in an object that finds reference in the Arcades Project as a metaphor for the defensive positioning of art in the intérieur (1999: I2, 3). However, in the narrative logic of the film serial, neither the suit of armor nor the vocaphone technology can step in as Elaine's legitimate savior. Instead, when Elaine takes the vocaphone from its hiding place to embrace it in the final moments of the episode, a split-screen of her on one side and Kennedy on the other attributes the guarding function back to the detective and affirms the serial's love plot. This split-screen image of the two characters, each with the vocaphone, visualizes the connection of different spaces through the vocaphone, but also through editing. In other terms, the presence of the vocaphone to a certain extent justifies and explains the technique of crosscutting. Moreover, the split-screen image aligns the spaces side by side that were, up to this point, shown in successive alternation. The shot thus reminds viewers not only of the connection between the protagonists but also of the simultaneity of the previously unfolding action. Placing the cut in the center of the frame, the instance 
exposes its own means of visual narration, exhibiting the operational aesthetic of cinematic storytelling through the operation of the vocaphone. This means of 'showing itself' furthermore disrupts the integrity of the intérieur: as Benjamin describes in the Arcades Project, the intérieur loses its status as a secluded private sphere as the boundaries between interior and exterior dissolve. In film, this relative homogenization is a result of the cinematic camera, which equally penetrates interior and exterior diegetic spaces. Through the split-screen at the end of the serial's eighth episode, the film foregrounds the omnipresence of the camera and, in connecting the filmic image to the vocaphone technology, it highlights the camera's surveillance function. The serial thus not only stages technological props such as the seismograph or the vocaphone with their capacities to record or monitor. Instead, the camera of twentieth-century film replaces the plush of the nineteenth-century intérieur: it records traces and presents them for analysis. In analyzing these traces, the film viewers collectively take up the task of detection.

\section{Seen Through the Periscope: Surveillance and Repetition}

The positive assessment of the vocaphone's surveillance function in THE EXPLOITS OF ElAINE runs counter to Benjamin's condemnation of similar practices. In the serial, the detective's ability to monitor the activities in Elaine's house provides a sense of security. Benjamin, by contrast, unearths a skepticism about the 'modern administrative apparatus' and its increasing, coordinated registration and control of law-abiding citizens in the writings of Baudelaire and Balzac (1999: 225; I6a, 4). Whereas Balzac lists the timetables of public coaches, the counting and stamping of letters, and the numbering of houses as examples of bureaucracy's expanding sway over the population of Paris, Benjamin adds anecdotal evidence according to which Baudelaire kept several addresses and moved from house to house to evade his creditors (1999: 225; I6a, 4; 2003b: 26). To Benjamin, Baudelaire is the enduring, now displaced flâneur who aims to vanish into the crowd 'against the government's effort to establish a multifarious web of registrations-a means of compensating for the elimination of traces that takes place when people disappear into the masses of the big cities' (2003b: 26). In a way, and without Benjamin's acknowledgment, the administrative apparatus with its photographic technology becomes the detective (cf. 2003b: 27). Meanwhile, in aiming towards evasion, Baudelaire appears on the side of the criminal (p. 26). The Exploits of Elaine similarly references the 
increasing surveillance practices of its own time, furthered by technological advancement, but it arrives at a different evaluation. Enabled by his technological prowess, Kennedy — as a scientist and inventor and not an agent of justice - provides for Elaine's safety. His act of surveillance is meant to provide security rather than exercise (political) control. Other instances in the serial, by contrast, refute a similarly simplistic association of surveillance and security. As the following examples will demonstrate, THE ExPLOITs OF ELAINE makes technologies of surveillance available to both the detective and the culprits. As I will show, the serial thereby questions the reliability of a technological registration of traces, and it encourages a reflection of cinema's own connection to surveillance practices. In this context, the serial eventually demonstrates the particular receptive practices afforded by detection and surveillance, which relate to repetition and seriality and which are crucial to the serial's operational aesthetic.

In chapter ten, 'The Life Current', the Clutching Hand tries to drive a wedge between Elaine and Kennedy in order to cause the detective to drop the case. The villain spreads news throughout the city that women were being poisoned by a kiss from a stranger. A female member of the villain's gang lures Kennedy to her apartment, telling him that she received the poisoned kiss and wants him to investigate. Before he arrives, she and a helper install a hidden camera in a stag's head that is mounted on the wall. When Kennedy arrives, the villain's henchwoman demonstrates how the poisoned kiss was given-she kisses Kennedy. Meanwhile, her helper operates the hidden camera to take compromising pictures of the situation. She will then show the images to Elaine, causing the love plot between Kennedy and her to stagnate.

On the one hand, this instance in the serial showcases the possibilities for surveillance that are enabled by film and photography. Simultaneously, the episode questions the truth claim of photography, as the camera captures an explicitly staged scene into which Kennedy is tricked. The scene rehearses for technologically mediated traces what the serial's initial chapter showed for non-technologically recorded ones: whereas the factitious fingerprints on the bust of Shakespeare in the serial's first episode point to the unreliability of non-mediated evidence, episode ten points to a similar manipulability of mediated, technologically recorded content. The serial thus depicts mediated traces as by no means more reliable than traditional ones, complicating the notion that technology makes up for the crowd's inability to bear traces. In this way, instead of opening a problem space and supplying the matching answer to recreate an earlier equilibrium, the serial refuses to solve modernity's riddles and revels in the complexity and 
contingency of options instead. ${ }^{13}$ What remains is a distinction of old and new. After all, the camera in this scene is no new and remarkable invention. As a familiar technology, photography and film are easy to manipulate, in opposition to Kennedy's more innovative devices.

The most efficient of devices in this scene, however, is once again the film camera that enables the serial's narrative in the first place. It allows for a full overview of the ongoing action and thereby itself emerges as an agent of surveillance. As in the first episode of the serial, this overview manifests itself in the film's presentational (as opposed to representational) approach to storytelling, and it coincides with an operational aesthetic. The hidden camera in the stag's head is shown in numerous close-ups that detail the positioning of the camera lens in the stag's eye and the shutter that can be operated from behind the wall. This detailed depiction outlines the technological set-up of the surveillance mechanism, the knowledge of which is a precondition for viewers to understand the villain's following orchestration of Kennedy's predicament. The explanation is thus necessary for the narrative, but the episode's chronological explanation and instantiation of the photographic contraption also underlines the surveillance function of the non-diegetic camera. This camera, in turn, mediates the traces, which mostly appear as recorded or monitored by ingenious inventions within the serial's world, to its cinema audience. Within the serial's world, Kennedy is the detective who interprets traces, and Elaine, as a viewer of the photographs of Kennedy that were produced under wrongful circumstances, falls for the trick and is therefore not a skilled detective herself. The viewers, by contrast, engage in efforts of detection through the traces provided by the surveilling camera, as it details the photographic contraption and reveals the scheme carried out by means of the diegetic photography. Instead of asking viewers to interpret a trace such as the photograph, the serial allows them to watch the production of the trace. It highlights the manufacturing of the trace by providing another group of traces, that is, close-ups of the trace-producing mechanism in the stag's head. Through the serial's operational aesthetic, film spectators thus become detectives who correlate traces from different levels of mediation and who, by means of these efforts, make sense of the story as it unfolds.

The status of the film camera as an agent of surveillance was not new when THE EXPLOITS OF ELAINE was released in 1915. The camera's surveillance

13 This reveling in contingency is a general trend with film serials in the silent and sound eras that surfaces, for instance, in the narrative mode of OFFICER 444 (Goodwill, 1926) or in the exhibition of a variety of media in sound-era serials (Brasch \& Mayer 2016; see also chapters five and six in this volume). 
function rather harks back to the earliest days of filmmaking, and it resonates with turn-of-the-century films about forced and stolen kisses. The story of the supposedly poisoned kiss in THE ExPLOITS OF ELAINE is in fact reminiscent of the Peeping Tom shorts of the cinema of attractions. Amanda A. Klein establishes what she calls the 'kissing cycle' in short films made between 1896 and 1906, which focus on and often joke about a kiss, including films like Edwin Porter's The Kiss (1900) or What Happened in the Tunnel (1903). Klein relates these films to the late-nineteenth-century newspaper coverage of so-called 'mashers': white middle-class men who, in urban environments, approached distinguished women on the street and stole usually unwelcome kisses. Newspapers reported critically and substantially on this and demanded new social rules, as the mashers mostly did not face any consequences (2016: 22-25). According to Klein, the kissing cycle of films provided the visual record that was lacking in the newspaper accounts of actual incidents, and it offered thematic variations. Films often envisioned alternative outcomes in which spontaneous women reversed the assault to frame the mashers. In What HAPPENED In THE TunNel, for example, a woman uses the time in the dark, when the train passes through a tunnel, to change places with her African-American maid. The masher thus mistakenly kisses the maid, which the film presents as a racial joke on the masher theme (Klein 2016: 35-37).

The contemporaneous audience's memory of the masher discourse makes the crook's story of the poisoned kiss in THE ExPLOITS OF ELAINE less unbelievable than it may seem, and Jameson's trust in the supposedly poisoned woman's claims now seems a little less far-fetched. The episode's story is very much in line with the puns and variations on the masher theme in the kissing cycle. Nevertheless, Klein also maintains that, especially in later kissing cycle films such as WHAT HAPPENED IN THE TUNNEL, the women typically do not kiss back but rather appear to be violated by the kiss. This, she maintains, inaugurates the male gaze in the kissing cycle (2016: 28f). Whereas The Exploits of ELAINE alters the gender relations by casting its male protagonist as being violated by the kiss, the serial in this instance retains the male perspective through the co-conspirator, who hides behind the wall to operate the camera's shutter. When Elaine finally looks at the resulting photographs, she is cast as both the voyeur of the images and the person violated by the trick.

Nevertheless, whoever's perspective we temporarily assume, they are all mediated by the surveilling, non-diegetic camera, and that perspective itself similarly harks back to the earliest days of moving picture production. According to Catherine Zimmer, turn-of-the-century films were often 'feats of surveillance', for instance WORKERs LEAVING THE FACTORY (1895), the Lumière Brothers' film of their employees' departure at the end of the 
work day (2011: 428-429). Films made in the United States often addressed the mediated act of watching by placing visual technologies in the frame, as in As Seen Through a Telescope (1900) or Photographing a Female СRоок (1904). Especially Edison's 'caught in the act' stories combined such self-reflexive voyeurism with portrayals of crime and sexuality, as in Interrupted Lovers (1898) or The KleptomaniaC (1905) (Gunning 1995a: 35; Zimmer 2015: 6). Drawing like Klein on the masher cycle film What Happened In the TunNel, Zimmer points out that the joke of the black maid taking the seat of her white employer during the dark frames in the tunnel 'is predicated on the failure and then reestablishment' of 'racial visibility and cinematic technology' (2015:11). ${ }^{14}$ Without integrating the film apparatus in its frames, WHAT HAPPENED IN THE TUNNEL nevertheless foregrounds cinema's surveillance capacities while also laying bare its limitations, particularly its reliance on lighting. The film's point of view thus acknowledges that the camera's perspective is at times unreliable, a tendency that culminates in trick films that show things that explicitly do not occur in a verisimilar filmic world, for instance in films like THE DoG FACtoRy (Porter, 1904) or A Trip to the Moon (Méliès, 1902).

Both the presentational storytelling of THE EXPLOITS OF ELAINE and its operational aesthetic depend on the promise of the film camera's surveillance perspective. The serial's commitment to showcasing technology and its revealing close-ups of the photographic contraption foster a trust in the cinematic image that suspends an awareness of film's capacity for trick filming. In its juxtaposition of trick photography and cinematic surveillance, THE EXPLOITS OF ElAINE refuses to participate in a general trend of transitional-era film in which, in Scott McQuire's terms, 'cinematic credibility shifted from emphasis on the geometrical plane of perspective to planes of fictive and narrative logic, a change Commolli aptly described as the movement from optical to psychological realism' (1998: 76). Instead of participating in this trend without comment, the serial addresses the shift by comparing and contrasting technologies and visual perspectives. Explaining its diegetic technologies as attractions and employing them as guidelines for an understanding of the following narrative, the serial draws on an optical realism that will help put its psychological appeal in place. Thus, in addition to inviting an emotional investment in its story, THE EXPLOITS OF ELAINE exemplifies how such emotional investment comes into

14 Zimmer's study at this point elaborates on the connection of race and surveillance and the production of race through surveillance as it harkens back to the pursuit of escaped slaves in the United States (2015: 11-13). 
being - an exemplification that, once again, draws on an all-encompassing camera perspective. Whereas other serials of the time share a comparable optical realism-for example in their insistence on breakneck stunts or in the showcasing of dangerous animals - and also self-consciously exemplify filmic storytelling, ${ }^{15}$ ELAINE's showcasing of the fabrication of fake images through an all-encompassing, all-conveying camera and its resulting juxtaposition of cinema's conflicting modes of address is unique. Particularly in its weekly demonstration of narrative technique through its showcased technologies and operational aesthetic, THE EXPLOITS OF ELAINE capitalizes on the serial format for a scheduled rehearsal of cinematic viewing practices.

The surveillant camera perspective occasionally poses a problem for a narrative that continuously promises but serially defers the identification of its cloaked master villain. The camera depicts the villain and his actions from the beginning and thus always threatens to prematurely reveal his identity. Hiding from the camera, the Clutching Hand is continuously in disguise, even in scenes that include no other character but himself (for instance in chapter one, 'The Clutching Hand'). The serial addresses the camera's threat by allowing the villain and the camera to engage playfully with notions of masking and unmasking. In episode nine, for example, Detective Kennedy attempts to remove the Clutching Hand's disguise by ripping the bandana off his face-only to reveal another bandana underneath. Earlier, in episode six, the serial highlights its dialectic of surveillance and concealment when it shows the Clutching Hand sitting on a chair, his back turned towards the camera, donning his coat and a facial disguise with slightly awkward motions because he cannot turn around and face the camera ('The Vampire'). His inelegant struggle to get dressed self-reflexively foregrounds the camera angle and the serial's visual technique of hiding the villain in plain sight. Again earlier, towards the end of the fourth episode, the viewers almost see the villain unmasked - he takes off his facial disguise, but the screen fades to black just in time to hide his face ('The Frozen Safe'). Such scenes tease the viewers, foster their interest in the villain's identity and in the upcoming episodes, and underline the filmmaker's capacity to decide when to reveal the villain's face. Moreover, they emphasize the fact that the camera itself is an agent with its own specific interests. ${ }^{16}$ At the same time, such instances

15 See in particular the presentational storytelling in THE PERILS OF PAULINE in Denson 2014b and in chapter three of this volume.

16 These instances in which the serial acknowledges the viewer's limited perspective oppose a conceptualization of the film spectator in terms of Foucault's panopticon, which presupposes a viewer's 'imagined visual omnipotence'. It was this panoptic concept of spectatorship that prompted Anne Friedberg's turn to the flâneur/flâneuse for visual culture studies (1998: 256). 
remind viewers that an image of the villain's face would be informative indeed. These instances thus self-reflexively point to the serial's paradox of a presentational practice of showing everything on the one hand and a rule of the camera perspective that veils elements on the other. As Gunning phrases it in another context, 'visuality and obscurity together define detective fiction and films' (2005: 74; italics in the original). Whereas the serial's diegetic technologies such as the vocaphone, the seismograph, or the hidden camera monitor and record traces, the camera perspective that enables the story manages the visibility and obscurity driving its narrative. This relation becomes especially pointed in chapter nine, 'The Death Ray', an episode that features a diegetic visual mechanism that rather closely resembles early film and that furthermore illustrates the relation of surveillance and moving image reception to the operational aesthetic and cinematic seriality.

The episode begins with a threatening letter from the Clutching Hand urging Elaine and Bennett to discharge Kennedy and have him leave the country. If the detective refuses to do so, the villain promises that a pedestrian will die outside of his laboratory every hour the following day. On the same day, Kennedy's recently ordered periscope is delivered to the laboratory. The detective explains how it works to Jameson in a scene that details the functioning of the mechanism and its installation in the window. After this introduction, the periscope is put to the task in a longer sequence in which the protagonists witness two pedestrians collapsing in the street. Both of them have been murdered by two of the Clutching Hand's co-conspirators, who operate a 'death ray' from another building. The death ray closely resembles the spotlights used in film production, but in the narrative world of the serial it issues a lethal beam of light, aimed with the help of regular binoculars. Overall, the scene pits multiple means of surveillance against each other: the detective surveils the street through the vocaphone, whereas the villains monitor both the street to aim their weapon and Kennedy's laboratory to check whether he signals his defeat.

The periscope in this chapter resembles a window mirror, a mechanism that Gunning describes was popular in nineteenth-century France. At the time, inhabitants of urban apartment buildings installed special mirrors in their windows to monitor their front doors. Relating it to Benjamin's notion of the intérieur, Gunning considers the window mirror a mechanism that made the exterior accessible to the inside space. He stresses that 'ultimately, the interior cannot withstand the exterior, it can only transform the nature of its looming invasion optically' (2003:107). The window mirror symbolizes a relation between intérieur and outside spaces that resembles the one instantiated by the vocaphone. It secures the intérieur by enabling a view 


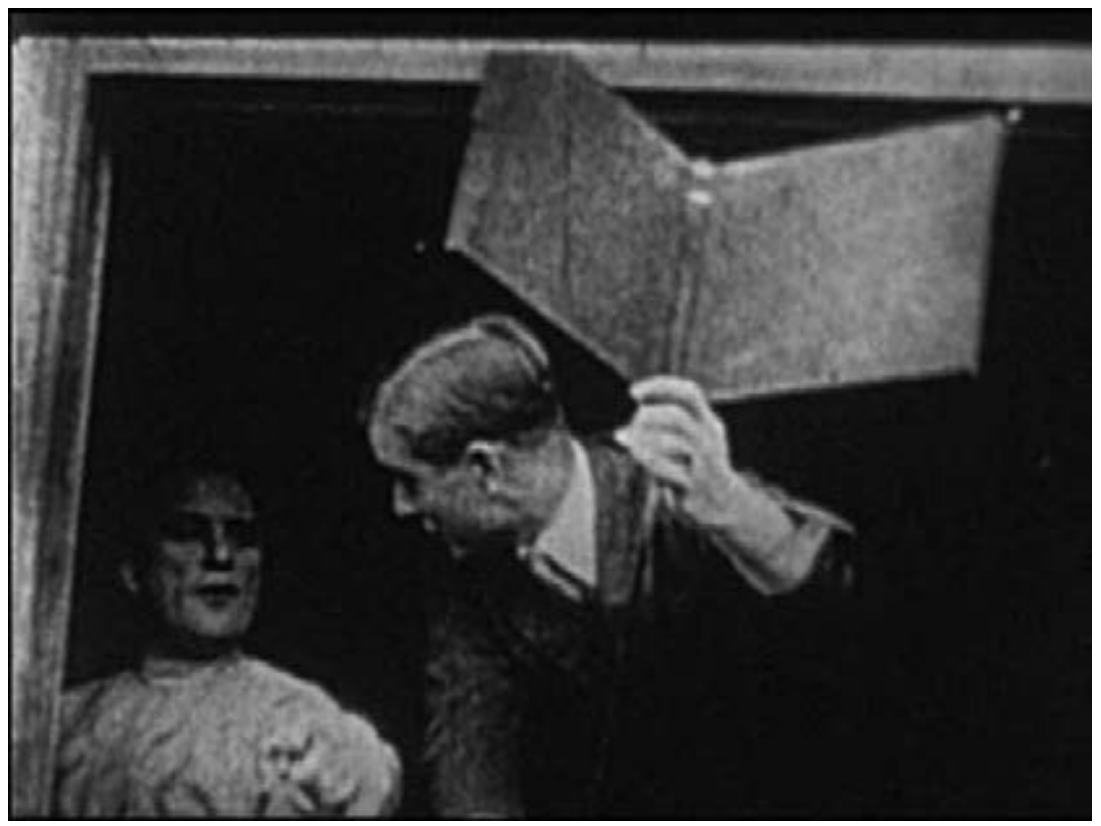

19. Jameson installs the periscope in the window (The Exploits of ElAINE, episode 9, 'The Death Ray').

of the front door, but it also threatens it by referencing the outside and, to an extent, letting that world access the interrieur. That access of the outside, through both the window mirror and the detective's periscope, is always mediated. Gunning arrives at a similar conclusion concerning optical toys more generally when he argues that 'the nineteenth-century parlor became $[\ldots]$ the locus of optical devices and philosophical toys of all sorts - the stereoscope, the kaleidoscope, the magic-lantern — that seem to open the viewer's gaze onto a different world, but only under the dominion of the image and semblance' (p. 107).

Kennedy's laboratory is no typical secluded parlor but a thoroughly modernized space. Nevertheless, the periscope transforms the vision of the street and protects the laboratory space, particularly from the view of the villains; and the characters within the laboratory share the voyeuristic interest in the outside vision of Benjamin's nineteenth-century bourgeois Parisians. Jameson is the first one to see a pedestrian die in the street, and he alerts Kennedy to the scene. When the second pedestrian dies an hour later, Elaine and her lawyer Bennett have joined Jameson and Kennedy, and they all wait to witness the next murder. Instead of ending the spectacle by displaying the requested signal for his defeat in the window, Kennedy 


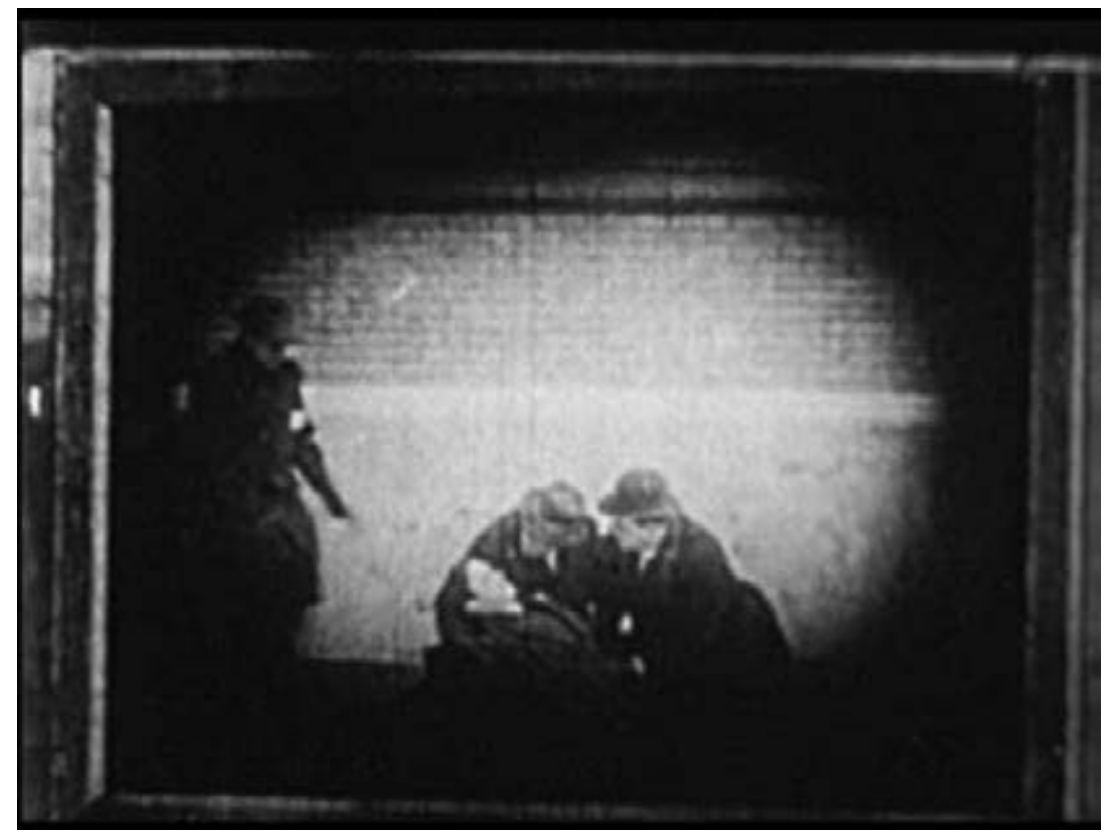

20. The serial depicts the action on the street as it is framed by the periscope (The Exploits of Elaine, episode 9, 'The Death Ray').

calls his friends to see it happen again. His behavior in this instance reflects the basic premise of serial cinema, that is, the urge to see the next episode. The periscope removes Kennedy and his companions from the reality of the action on the street and thereby in a way obscures the macabre notion of the scene. Meanwhile, the serial's characters engage in a task that the serial's spectators know too well: the repeated engagement with a mediated image.

The characters' viewing of two high-angle takes of a street scene is again reminiscent of early film practices. Gunning refers to turn-of-the-century actuality shorts that showed streets that were familiar to their spectatorship. Advertisements for such films at the time stressed the possibility of watching these films numerous times, arguing that the repetition of the film would provide spectators with an opportunity to study the scene (Gunning 1997: 35). In a similar manner, Kennedy may be watching the repeated murder as a means to analyze the villain's approach. Watching a second pedestrian die verifies that the original incident really happened, and it provides Kennedy with an opportunity to study the incident. Repetition is therefore not simply a strategy of producing economically profitable popular-cultural artifacts, it is also a narrative strategy that influences the 
film experience in multifarious ways. As Ruth Mayer stresses, 'by now, in the wake of Umberto Eco's and other critics' reflections on the principles of serial narration, it is almost a truism to insist on the productive effect of repetition and reiteration, especially in popular culture' (2014: 124). Admittedly, the view of the second murder is not an exact repetition but a highly reiterative second installment, because a second person is being murdered after all. However, even the exact repetition of already viewed actuality footage would engender a slight variation, as it designates the earlier viewing as the initial one. As Gilles Deleuze explains, exact repetition is impossible, as even with minute duplications the mere knowledge of the existence of a prototype, which with the existence of its double loses its singularity, necessarily alters the reception experience (2007: 15-25). Repetition and variation are thus necessarily intertwined, and their distinction is one of degree rather than kind (cf. Eco; Jahn-Sudmann \& Kelleter 2012: 206). Serial narratives in general, but in particular the periscope scene in The Exploits of Elaine, propel the story forward through repetition, performing what Frank Kelleter terms 'the cultural work of repetitively varying narration' (2012a: 13). ${ }^{17}$ In a continuation of ELAINE's efforts to demonstrate its own conditions of storytelling, the viewing of the second murder itself pinpoints how repetition changes its original, as the second murder affirms the villain's intention and persistence. Nevertheless, instead of becoming productive in its reformulation as variation, repetition itself and repeated viewing occasion an operational aesthetic by offering a means of analyzing the image. After all, Kennedy's view of the second murder enables him to analyze the ongoing action just as the serial's narrative formula reveals itself to returning viewers through its weekly repetition. The murder watched twice in THE EXPLOITS OF ELAINE points to the demonstrative, presentational quality of film serials, which spectators enjoy not despite their repetitive nature but because of it. In other words, in relation to both Kennedy and the film viewers, repetition turns the flâneur into a detective.

In this episode and in The Exploits of ELAINE more generally, repetition takes on a number of functions, including, as the following paragraphs will illustrate, excess, outbidding, irony, and a self-reflexive engagement with seriality. First and foremost, repetition itself can be a source of pleasure. As Mayer points out when she describes possible modes of engagement with narratives about Fu Manchu, 'the ideal approach

17 The original quote, in German: 'Es geht um die kulturelle Arbeit wiederholt variierenden Erzählens selbst' (Kelleter 2012a: 13). 
[...] is not to read for the plot, or rather, not to read for the plot alone. Yet the text does not foster analytical detachment either: It is all about the pleasures of recognition, actualization, reiteration and appropriation' (Mayer 2014: 95). Reiteration as such and its recognition inform the reception experience enabled by film serials in similar ways. The repeated, somewhat morbid viewing of the death of one, then a second pedestrian in ThE Exploits of ElAINE, I argue, points to the pleasure of reiteration-a pleasure that likewise informs the experience of watching a film serial as a whole. Eco points to the pleasure of repetition when he recounts a past rejection of the study of mass-cultural artifacts in what he calls 'modern aesthetics':

A popular song, a TV commercial, a comic strip, a detective novel, a Western movie were seen as more or less successful tokens of a given model or type. As such they were judged as pleasurable but non-artistic. Furthermore, this excess of pleasurability, repetition, lack of innovation, was felt as a commercial trick (the product had to meet the expectations of its audience), not as the provocative proposal of a new (and difficult to accept) world vision. (Eco 1985: 162 $)^{18}$

More than a simple list of the supposed commercial tricks of popular culture, I consider Eco's notions of repetition and an excess of pleasurability as interdependent. After all, commercial popular culture naturally revels in the repetition of likeable elements that attract a returning audience. Excess, particularly of emotionality and pathos, is a significant element of film's melodramatic mode of storytelling, which originated in French stage traditions and informed American filmmaking in general and serials in particular (Brooks 1995; L. Williams 1998; Kelleter, Mayer, \& Krah 2007; for melodrama and silent serials, see Singer 2001). The repetition of pleasurable, already excessive elements then constitutes the excess of serial narratives, which in a sense augment the excess of the melodramatic mode through its weekly reinforcement. ${ }^{19}$ At the same time, it is this weekly rendition that lays bare the process of melodramatic storytelling and thereby occasions the serial's operational aesthetic.

18 Although Eco is right that this distinction of repetition and innovation, mass culture and high art, did and does exist in scholarship, we have to bear in mind that three years prior to the release of THE EXPLOITS OF ELAINE, cinematic seriality itself was the innovation, just as repetition was the innovation with the street scene actualities described by Tom Gunning.

19 For a more detailed account of serials and melodrama, see chapter five of this volume. 
While fostering melodrama, excessive repetition can also tend towards irony, and an ironic reading of the murder of two uninvolved pedestrians is another possible engagement with the scene. In his philosophical critique of repetition and difference, Deleuze argues that 'repetition is a thing of humor and irony' and that transgression and exceptionality are part of its nature (2007: 20). In the same vein, Frank Kelleter and Andreas Jahn-Sudmann acknowledge in their analysis of twenty-first-century television series that seriality at times provokes ironic readings. In their account, serial narratives 'repeatedly intensify the successfully established markers of distinction' that differentiate one series from another and as a result at times border on the socially unacceptable (2012:207). In this context, irony emerges as a narrative's reaction to its own tendency to outbid both its own earlier episodes and other series (p. 214). In ThE Exploits of ElAINE, spectacular thrill effects continuously aim to surpass the violence and sensationalist appeal of earlier episodes. Elaine is frequently bound and gagged; she shoots a henchman of the Clutching Hand; and we almost witness a secret blood transfusion to save that henchman, among other scenes that rival one another (episode six, 'The Vampire'). The two murders of unknowing, uninvolved bystanders take the violence of the serial and its diegetic villain to new extremes. Moreover, the increasing 'audience' of these murders, especially as Elaine and Bennett join to watch the second attack, foreground the voyeurism that is involved in outbidding. In this episode, the serial relieves its own combination of outbidding and repetition - and the resulting increase in violence — through a self-reflexive acknowledgment of its own repetitious character. The periscope scene thus exemplifies Kelleter and Jahn-Sudmann's argument that repetition as an originally 'quantitative operation [...] eventually culminates in metaserial intelligence' (p. 208). The result of such meta-serial moments is a narrative practice that the authors, with reference to Jason Mittell, call an 'operational' or 'procedural' aesthetic that foregrounds the mechanics of storytelling (p. 213).

The viewer's recognition of repetitive filmic practices precludes neither an appreciative reception experience nor ironic readings. Nevertheless, the engagement with the serial narrative takes place with the viewer's full knowledge of the story's commercial, episodic character. Kelleter and Jahn-Sudmann consider this awareness itself a result of outbidding and, more generally, of scenes that emphasize their own serial structure and options for continuation. The authors further stress the importance of such meta-serial reflections for studies of serial narratives, arguing that 'if we want to understand how invariance and variability interrelate, we 
should also consider the recursive dynamic of serial narratives, that is their tendency to (medial) self-observation' (2012: 207). ${ }^{20}$

In ELAINE's tenth episode, this meta-seriality coincides with the selfreflexive acknowledgment of the media apparatus through the periscope image and the integration of the spotlight, which doubles as the villain's 'death ray', in the frame. The view that the periscope provides resembles filmic perception in its fixed visual frame and perspective, and because it enables communal viewing. ${ }^{21}$ By way of referencing the filmic apparatus, the serial foregrounds not only its own seriality but cinema's capacity for serial storytelling more generally. It highlights the fact that film allows for repetition in a way that is in line with the advertisement of the repeated viewing of actualities as described by Gunning. Twenty years into the history of motion picture projection, THE EXPLOITS OF ELAINE stressed a capacity that characterized the filmic medium from the start. This curious correlation of retrospectivity and the comparative novelty of film serials in fact resonates with the paradoxical challenge of 'practicing reproduction as innovation' that serial narratives face more generally (Jahn-Sudmann and Kelleter 2012: 207). The distinction of repetition and variation collapses at this point as The Exploits of ElAine, very much in line with Deleuze's observations on repetition, turns repetition into a novelty (cf. Deleuze 2007: 20-21).

Instead of enabling detection through broad overview perspectives, THE EXPLOITS OF ELAINE rehearses the viewers' efforts of detection through a repetitive weekly application and practice. The serial thereby makes up for the rejection of supervision that it shares with other silent-era serials (cf. Brasch \& Mayer: 2016). It replaces high-angle views with point-of-view shots, thereby urging the viewers to arrive at an understanding of the portrayed spaces for themselves. THE EXPLOITS OF ELAINE thus harks back to viewers' detective efforts of earlier decades. As mentioned before, Gunning connects the analytic affordances of the detective with repetition when he quotes an 1896 advertisement for a film projector called the Jenkins Phantoscope, which highlights the possibility for repeat viewings and thereby evidences how the advent of the motion picture transformed modernity's kaleidoscopic

20 Original quote: 'Möchte man verstehen, wie sich Invarianz und Variabilität in Serien zueinander verhalten, sollte man auch die rekursive Dynamik serieller Erzählungen berücksichtigen, also ihren Hang zur (medialen) Selbstbeobachtung oder abstrakter gesprochen: das eigendynamische Moment ihrer Evolution, ermöglicht durch ein konstant mitlaufendes Reflektieren auf die Bedingungen und Möglichkeiten der eigenen Fortsetzbarkeit' (Jahn-Sudmann \& Kelleter 2012: 207).

21 In a more futuristic reading, it also points to the live-experience enabled later by television and to its placement in the communal parlor. 
viewings of endlessly reorganizing street scenes: 'The motion picture intervenes on this scene, not by organizing it, but by capturing it in a form which allows endless repetition, opening the way for a studied apperception' (Gunning 1997: 35).

Meanwhile, ELAINE's weekly introduction of a new technology offers both variation and a means of reflecting upon a mechanism's respective means of monitoring or recording. The latter results in a reflection of the perspective of surveillance itself. Gunning describes this activity in the context of Benjamin's writing on the panopticon: 'The nineteenth-century detective not only observes and investigates but also — at least potentially—investigates his or her point of view' (2003:110). The spectating position of the detective thus implies a recursive moment that reflects its own perspective of observation, detection, or surveillance. Whereas all films potentially invite such recursive self-reflexivity, its weekly rehearsal in THE ExPLOITS OF ELAINE not only enables film viewers to become detectives but trains and reinforces their detective skills. Whereas the emerging feature film was aimed at single viewings, the film serial capitalized on seriality's dialectic of repetition and variation. The variation between individual episodes provided an opportunity to transpose the analytic benefits of repetition while integrating it —in the form of succeeding rather than straightforwardly repeating chapters - into the changing realities of motion picture exhibition.

Because of its introduction of novel or fictional mechanisms and the concomitant self-reflexivity of cinematic narration and presentation within the highly repetitive form of the film serial, The Exploits of Elaine particularly encourages and rewards its viewers' efforts at operational detection. Instead of having the diegetic detective interpret the clues for the film viewers, the camera grants the viewers a look for themselves and thereby turns them into detectives in Benjamin's sense of the term. In the long run, the frequent repetition of the serial's form and of the viewer's assigned task provides the viewing experience with a machinic momentum, which defines the operationality of the detective effort and which, in its intensity, is unique to film serials and which continued to inform them long after THE EXPLOITS OF ELAINE played in local cinemas.

\section{Bibliography}

As Seen Through a Telescope. Dir. George Albert Smith. G.A. Smith, 1900.

A Trip to the Moon. Dir. Georges Méliès. Perf. Bleuette Bernon, François Lallement, Georges Méliès. Star Film Company, 1902. 
Benjamin, Walter. 1999. The Arcades Project (1927-1940). Translated by Howard Eiland and Kevin McLaughlin. Cambridge, MA: The Belknap Press of Harvard University Press.

—. 2003a. "On Some Motifs in Baudelaire (1940)." In Walter Benjamin: Selected Writings, edited by Howard Eiland and Michael W. Jennings, Volume 4, 1938-1940: 313-55. Cambridge, MA: Harvard University Press.

—. 2003b. "The Paris of the Second Empire in Baudelaire (1938)." In Walter Benjamin: Selected Writings, Volume 4, 1938-1940: 3-92. Cambridge, MA: Harvard University Press.

Brasch, Ilka, and Ruth Mayer. 2016. "Modernity Management: 1920s Cinema, Mass Culture and the Film Serial." Screen 57 (3).

Brooks, Peter. 1995. The Melodramatic Imagination: Balzac, Henry James, Melodrama, and the Mode of Excess. New Haven: Yale University Press.

Buck-Morss, Susan. 1989. The Dialectics of Seeing: Walter Benjamin and the Arcades Project. Cambridge, MA: The MIT Press.

Dahlquist, Marina. 2013. “Introduction: Why Pearl?" In Exporting Perilous Pauline: Pearl White and the Serial Film Craze, edited by Marina Dahlquist, pp. 1-24. Chicago: University of Illinois Press.

Deleuze, Gilles. 2007. Differenz und Wiederholung. Paderborn: Fink.

Denson, Shane. 2014. "The Logic of the Line Segment: Continuity and Discontinuity in the Serial-Queen Melodrama." In Serialization in Popular Culture, edited by Robert Allen and Thijs van den Berg, pp. 65-79. New York: Routledge.

Denson, Shane, and Ruth Mayer. 2012a. "Bildstörung: Serielle Figuren Und Der Fernseher." Zeitschrift Für Medienwissenschaften 7 (2): 90-102.

—. 2012b. "Grenzgänger: Serielle Figuren Im Medienwechsel." In Populäre Serialität: Narration - Evolution - Distinktion, edited by Frank Kelleter, pp. 185-203. Bielefeld: transcript.

Dick Tracy. Dir. Alan James and Ray Taylor. Perf. Smiley Burnette, Ralph Byrd, Kay Hughes. Republic, 1937 .

Douglas, Diane M.1982. "The Machine in the Parlor: A Dialectical Analysis of the Sewing Machine." The Journal of American Culture 5 (1): 20-29.

Eco, Umberto. 1985. “Innovation and Repetition: Between Modern and Post-Modern Aesthetics." Daedalus 114 (4): 161-84.

Fantômas. Dir. Louis Feuillade. Perf. Edmund Breon, Georges Melchior, René Navarre. Gaumont, 1913.

Friedberg, Anne. 1993. Window Shopping: Cinema and the Postmodern. Berkeley and Los Angeles: University of California Press.

—. 1998. "The Mobilized and Virtual Gaze in Modernity: Flâneur/ Flâneuse." In The Visual Culture Reader, edited by Nicholas Mirzoeff, pp. 253-62. London and New York: Routledge.

Gunning, Tom. 1995a. "Crazy Machines in the Garden of Forking Paths: Mischief Gags and the Origins of American Film Comedy." In Classical Hollywood Comedy, edited by Kristine Brunovska Karnick and Henry Jenkins, pp. 87-105. New York: Routledge.

—.1995b. "Tracing the Individual Body: Photography, Detectives, and Early Cinema." In Cinema and the Invention of Modern Life, edited by Leo Charney and Vanessa R. Schwartz, pp. 15-45. Berkeley and Los Angeles: University of California Press.

-. 1997. "From the Kaleidoscope to the X-Ray: Urban Spectatorship, Poe, Benjamin, and Traffic in Souls (1913)." Wide Angle 19 (4): 25-61.

—. 2003. "The Exterior as Interieur: Benjamin's Optical Detective." Boundary 230 (1): 105-30.

- 2005. "Lynx-Eyed Detectives and Shadow Bandits: Visuality and Eclipse in French Detective Stories and Films before WWI." Yale French Studies 108: 74-88.

Hansen, Miriam. 1987. "Benjamin, Cinema and Experience: 'The Blue Flower in the Land of Technology.” New German Critique 40: 179-224. 
Interrupted Lovers. Dir. William Heise. Edison, 1896.

Jahn-Sudmann, Andreas, and Frank Kelleter. 2012. "Die Dynamik Serieller Überbietung: Amerikanische Fernsehserien Und Das Konzept Des Quality-TV." In Populäre Serialität: Narration - Evolution - Distinktion: Zum Seriellen Erzählen Seit Dem 19.Jahrhundert, edited by Frank Kelleter, pp. 205-24. Bielefeld: Transcript.

Kelleter, Frank. 2012. "Populäre Serialität: Eine Einführung.” In Populäre Serialität: Narration Evolution - Distinktion: Zum Seriellen Erzählen Seit Dem 19.Jahrhundert, pp. 11-46. Bielefeld: transcript.

Kelleter, Frank, Ruth Mayer, and Barbara Krah, eds. 2007. Melodrama! The Mode of Excess from Early America to Hollywood. Heidelberg: Universitätsverlag Winter.

The Kiss or May Irwin Kiss. Dir. William Heise. Perf. May Irwin, John Rice. Edison, 1896.

Klein, Amanda A. 2016. "The Kissing Cycle, Mashers, and (White) Women in the American City." In Cycles, Sequels, Spin-offs, Remakes, and Reboots: Multiplicities in Film and Television, edited by Amanda Ann Klein and R. Barton Palmer, pp. 22-40. Austin, TX: University of Texas Press. L’Arroseur Arrosé. Dir. Louis Lumière. Perf. François Clerc, Benoît Duval. Lumière, 1895.

Mayer, Ruth. 2014. Serial Fu Manchu: The Chinese Supervillain and the Spread of Yellow Peril Ideology. Philadelphia: Temple University Press.

McQuire, Scott. 1998. Visions of Modernity: Representation, Memory, Time and Space in the Age of the Camera. London: SAGE.

Motion Picture News. 1914. "Pathé Serial Marks Era in Film History,” December 19.

—. 1915a. "Remarkable Mechanical Devices Used in "Elaine," March 6.

-. 1915b. "Banquet Ends Pathé Exchange Convention," July 31.

Motography. 1915. "Remarkable Machines Shown," March 6. Media History Digital Library.

Münsterberg, Hugo. 1915. “Why We Go to the 'Movies.” Cosmopolitan, December. HathiTrust.

Officer 444. Dir. Francis Ford. Perf. Al Ferguson, Neva Gerber, Ben Wilson. Ben Wilson/Goodwill, 1926.

Panek, LeRoy Lad. 2006. The Origins of the American Detective Story. Jefferson, NC: McFarland.

Pangburn, Clifford H. 1915. "The Exploits of Elaine (Pathe - Fifth Episode)." Motion Picture News, February 6.

Photographing a Female Crook. Dir. Wallace McCutcheon. American Mutoscope \& Biograph, 1904.

Poe, Edgar Allan. 1841. "The Purloined Letter." In The Works of Edgar Allan Poe, Vol. 1, edited by John H. Ingram, pp. 494-513. London: A\&C Black.

Schwartz, Vanessa R. 1998. Spectacular Realities: Early Mass Culture in Fin-de-Siècle Paris. Berkeley and Los Angeles: University of California Press.

Singer, Ben. 2001. Melodrama and Modernity: Early Sensational Cinema and Its Contexts. New York: Columbia University Press.

Spigel, Lynn. 1992. Make Room for TV: Television and the Family Ideal in Postwar America. Chicago and London: University of Chicago Press.

Stamp, Shelley. 2000. Movie-Struck Girls: Women and Motion Picture Culture after the Nickelodeon. Princeton: Princeton University Press.

The Amazing Exploits of the Clutching Hand. Dir. Albert Herman. Perf. Rex Lease, Ruth Mix, Jack Mulhall. Weiss, 1936.

The Carter Case. Dir. William F. Haddock, Donald MacKenzie. Perf. Marguerite Marsh, Herbert Rawlinson, Ethel Grey Terry. Oliver Films, 1919.

The Dog Factory. Dir. Edwin S. Porter. Edison, 1904.

The Exploits of Elaine. Dir. Louis J. Gasnier, George B. Seitz, Leopold Wharton, and Theodore Wharton. Perf. Arnold Daly, Creighton Hale, Pearl White. Pathe, 1914-1915. 
The House of Hate. Dir. George B. Seitz. Perf. John Webb Dillon, Antonio Moreno, Pearl White. Astra/Pathe, 1918.

The Kleptomaniac. Dir. Edwin S. Porter. Perf. Aline Boyd, Phineas Nairs, Jone Stewart. Edison, 1905. The New Exploits of Elaine. Dir. Louis J. Gasnier, Leopold Wharton, Theodore Wharton. Perf. Arnold Daly, Creighton Hale, Pearl White. Pathe, 1915.

The Perils of Pauline. Dir. Louis J. Gasnier and Donald MacKenzie. Perf. Paul Panzer, Pearl White, Crane Wilbur. Eclectic/Pathe, 1914.

The Radio Detective. Dir. William James Craft, William A. Crinley. Perf. Jack Dougherty, Jack Mower, Margaret Quimby. Universal, 1926.

The Romance of Elaine. Dir. George B. Seitz, Leopold Wharton, Theodore Wharton. Perf. Arnold Daly, Creighton Hale, Pearl White. Pathe, 1915.

Trahair, Lisa. 2004. “The Narrative-Machine: Buster Keaton's Cinematic Comedy, Deleuze's Recursion Function and the Operational Aesthetic." Senses of Cinema, no. 33. http://sensesofcinema. com/2004/33/keaton_deleuze/\#8.

What Happened in the Tunnel. Dir. Edwin S. Porter. Perf. Gilbert M. Anderson, Bertha Regustus. Edison, 1903 .

Williams, Linda. 1998. "Melodrama Revised." In Refiguring American Film Genres: History and Theory, edited by Nick Browne, pp. 42-88. Berkeley and Los Angeles: University of California Press.

Workers Leaving the Factory. Dir. Louis Lumière. Lumière, 1895.

Young, Paul. 2003. "Media on Display: A Telegraphic History of Early American Cinema." In New Media 1740-1915, edited by Lisa Gitelman and Geoffrey B. Pingree, pp. 229-64. Cambridge, MA: MIT Press.

Zimmer, Catherine. 2011. "Surveillance Cinema: Narrative between Technology and Politics." Surveillance \& Society 8 (4): 427-40.

-. 2015. Surveillance Cinema. New York and London: New York University Press. 
